\title{
Early and Continuing Effects of Combined Alpha and Beta Irradiation of the Lung
}

Phase II Report

Manuscript Completed: January 1988

Date Published: March 1988

Prepared by

B.R. Scott, F.F. Hahn, M.B. Snipes

G.J.Newton, A.F. Eidson, J.L. Mauderly, B.B. Boecker

S.S. Yaniv, NRC Project Manager

Inhalation Toxicology Research Institute

Lovelace Biomedical and Environmental Research Institute

P.O. Box 5890

Albuquerque, NM 87185

\section{Prepared for}

Division of Regulatory Applications

Office of Nuclear Regulatory Research

U.S. Nuclear Regulatory Commission

Washington, DC 20555

NRC FIN A1203 


\section{DISCLAIMER}

This report was prepared as an account of work sponsored by an agency of the United States Government. Neither the United States Government nor any agency Thereof, nor any of their employees, makes any warranty, express or implied, or assumes any legal liability or responsibility for the accuracy, completeness, or usefulness of any information, apparatus, product, or process disclosed, or represents that its use would not infringe privately owned rights. Reference herein to any specific commercial product, process, or service by trade name, trademark, manufacturer, or otherwise does not necessarily constitute or imply its endorsement, recommendation, or favoring by the United States Government or any agency thereof. The views and opinions of authors expressed herein do not necessarily state or reflect those of the United States Government or any agency thereof. 


\section{DISCLAIMER}

Portions of this document may be illegible in electronic image products. Images are produced from the best available original document. 
F. F. Hahn, Inhalation Toxicology Research Institute, "Early Mortality Estimate for Different Nuclear Accidents," U. S. NRC Report NUREG/CR-0774, August 1979. Available for purchase from National Technical Information Service, Springfield, VA 22161.

B. R. Scott, et al.. Inhalation Toxicology Research Institute, "Experimental Studies of the Early Effects of Inhaled Beta-Emitting Radionuclides for Nuclear Accident Risk Assessment - Phase II Report," U. S. NRC Report NUREG/CR-5025, November 1987. Available for purchase from National Technical Information Service, Springfield, VA 22161.

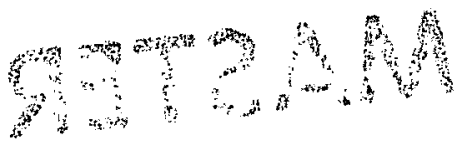


This report summarizes an inhalation exposure experiment that concerns early and continuing effects of combined alpha and beta irradiation of the lung of rats. Both morbidity at 18 months and mortality within 18 months after exposure were examined for rats exposed to the beta-emitter $147 \mathrm{Pm}$, the alpha-emitter $238 \mathrm{pu}$, or both combined. The results were used to validate hazard-function models that were developed (1) for pulmonary functional morbidity at 18 months and (2) for lethality from radiation pneumonitis and pulmonary fibrosis within 18 months. Both models were found to adequately predict the experimental observations after combined chronic alpha and beta irradiation of the lung. A relative biological effectiveness of approximately 7 was obtained for ${ }^{238} \mathrm{Pu}$ alpha radiation compared to $147 \mathrm{Pm}$ beta radiation for both pulmonary functional morbidity and lethality from radiation pneumonitis and pulmonary fibrosis. 
.

. 
EXECUTIVE SUMMARY . . . . . . . . . . . . . . . . . . . . . . . . . . . . 1

CHAPTER 1 - INTRODUCTION . . . . . . . . . . . . . . . . . . . . . . 3

CHAPTER 2 - METHODS . . . . . . . . . . . . . . . . . . . . . . . . . . . . 4

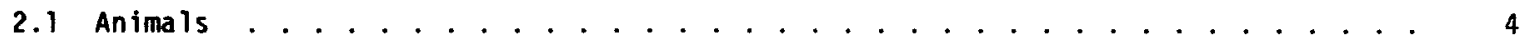

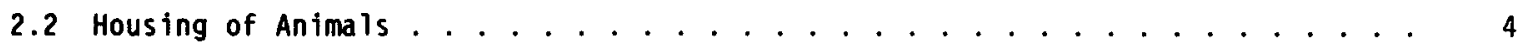

2.3 Experimental Design . . . . . . . . . . . . . . . . . . . . . . . . . . . . . 4

2.4 Biological Measurements . . . . . . . . . . . . . . . . . . . . . . 5

2.5 Aerosol Preparation and Generation . . . . . . . . . . . . . . . . . . . . . . 6

2.6 Total-Body Counting . . . . . . . . . . . . . . . . . . . . . . . . 6

2.7 Determination of Lung Radioactivity Content . . . . . . . . . . . . . . . . . . 6

2.8 Estimation of Initial Lung Burdens......................... . 8

2.9 Estimation of Doses to Lung . . . . . . . . . . . . . . . . . . . . . . 8

CHAPTER 3 - RESULTS . . . . . . . . . . . . . . . . . . . . . . . . . . 10

3.1 Initial Activity, Biological Clearance and Retention of Radioactive Material in the Lung.......................... . 10

3.2 Mortality Distribution . . . . . . . . . . . . . . . . . . . . . . 13

3.3 Expected and Observed Deaths . . . . . . . . . . . . . . . . . . . 15

3.4 Morbidity . . . . . . . . . . . . . . . . . . . . . . . . . . 16

3.4.1 Body Weight Changes . . . . . . . . . . . . . . . . . . . . . . . . . . 16

3.4 .2 Hematology . . . . . . . . . . . . . . . . . . . . . . . 16

3.4.3 Respiratory Function ....................... . 19

CHAPTER 4 - CONCLUSIONS . . . . . . . . . . . . . . . . . . . . . . . . 25

REFERENCES . . . . . . . . . . . . . . . . . . . . . . . . . . . . . . 26

APPENDIX: DATA BASES . . . . . . . . . . . . . . . . . . . . . . . . . . 27 


\section{LIST OF FIGURES}

3.1 Pulmonary retention of $238 \mathrm{Pu}$ in $\mathrm{F344/Crl}$ rats after (a) inhalation exposure to $238 \mathrm{Pu}$ on $7 y$. in fused aluminosilicate particles and after (b) inhalation exposure to mixtures of $238 \mathrm{pu}+$ $147 \mathrm{Pm}$ in the same fused aluminosilicate particle matrix.

3.2 Pulmonary retention of $147 \mathrm{Pm}$ in the lung of $F 344 / \mathrm{Cr}$ rats after (a) inhalation exposure to $147 \mathrm{Pm}$ on $7 y$, in fused aluminosilicate particles and after (b) inhalation exposure to mixtures of $238 \mathrm{Pu}+147 \mathrm{Pm}$ in the same fused aluminosilicate particle matrix.

3.3. Fitted two-component exponential curves for calculating, as a function of time after inhalation exposure, rads per $\mathrm{nCi} / \mathrm{g}-\mathrm{lung}$ due to $238_{\mathrm{Pu}}$ initially deposited in the lung (IL8). Separate curves are provided for exposure to "238pu only" and for exposure to "238pu $+147 \mathrm{Pm}$." To get cumulative rads to the lung at a specified time, multiply the value of the curve at that time by the initial lung burden for $238 \mathrm{pu}$ in $\mathrm{nCi} / \mathrm{g}-1$ ung.

3.4 Fitted two-component exponential curves for calculating, as a function of time after inhalation exposure, rads per $\mu \mathrm{Ci} / \mathrm{g}$-lung due to $147 \mathrm{Pm}$ initially deposited in the lung (ILB). Separate curves are provided for exposure to "147.pm on $7 y "$ and for exposure to "238pu $+{ }^{147} \mathrm{pm}$." To get cumulative rads to the lung at a specified time, multiply the value of the curve at that time by the initial lung burden for $147 \mathrm{Pm}$ in $\mu \mathrm{Ci} / \mathrm{g}-1$ ung.

3.5 Unadjusted (UNADJ) distribution of 1.5 year mortality from all causes of death (except sacrifices) as a function of exposure level. Adjusted values (ADJ) to correct for spontaneous effects are also given and were calculated assuming independence of radiation-induced and nonradiation-induced effects.

3.6 Survival time for death from all causes except radiation pneumonitis and pulmonary fibrosis as a function, of the intial lung burden of $238 \mathrm{Pu}$ in $\mathrm{nCi} / \mathrm{g}-1$ ung and $147 \mathrm{Pm}$ in $\mu \mathrm{Ci} / \mathrm{g}-1 \mathrm{ung}$. Time to euthanasia of morbid rats was used as estimates of time to death from radiation-induced and natural causes.

3.7 Survival time for death from radiation pneumonitis and pulmonary fibrosis. Time to euthanasia of morbid rats was used as an estimate of time to death from radiation induced causes.

3.8 Average body weight in grams, as a function of the exposure level, evaluated at 3 months after inhalation exposure; (a) males, (b) females.

3.9 Average body weight in grams, as a function of exposure level, evaluated at 6 months after inhalation exposure; (a) males, (b) females.

3.10 Average body weight in grams, as a function of exposure level, evaluated at 12 months after inhalation exposure; (a) males, (b) females. 
3.11 Average value for vital capacity in $\mathrm{ml}$, as a function of the exposure level, evaluated at 1.5 years after inhalation exposure; (a) males. (b) females.

3.12. Average value for co diffusing capacity per $\mathrm{kg}$ body weight, as a function of the exposure leve 1, at 1.5 years after inhalation exposure, and expressed in $\mathrm{ml} / \mathrm{min} / \mathrm{mmHg} / \mathrm{kg}$; (a) males, (b) females.

3.13 Average value for quasistatic compliance (CQ10), in $\mathrm{ml} / \mathrm{cmH}_{2} \mathrm{O}$, as a function of the exposure level, at 1.5 years after inhalation exposure; (a) males, (b) females.

3.14 Average value for slope of phase III of the single breath nitrogen washout curve expressed in $\times \mathrm{N}_{2} / \mathrm{ml}$, as a function of the exposure level, at 1.5 years after inhalation exposure: (a) males, (b) females.

3.15 Dose-effect surface for $F 344 / C r l$ rats for estimating the 1.5 -year lethality risk for death from radiation pneumonitis and pulmonary fibrosis after inhalation exposure to mixtures of $238 \mathrm{pu}+147 \mathrm{Pm}$ inhaled in an insoluble form. Results are based on the hazard-function mode1. Doses represent 1.5 -year doses to the lung.

3.16 Dose-effect surface for $F 344 / C r l$ rats for estimating the prevalence of respiratory morbidity at 1.5 years after inhalation exposure to mixtures of $238 \mathrm{Pu}+147 \mathrm{Pm}$ inhaled in an insoluble form. Doses represent 1.5-year doses to the lung. 
LIST. OF TABLES

$2.1238 \mathrm{Pu}-\mathrm{A}$ pha and 147Pm-Beta Study Design and 1.5 Year Survivors Among F344/Crl Rats, Expressed by Exposure Level

2.2 Survivors That Were Subjected to Pulmonary Function Testing at 1.5 Years After Inhalation Exposure

2.3 Aerosol Concentrations, Aerosol Size, Exposure Run Time and Initial Radionuclide to 169yb Activity Ratios by Experiment Number

3.1 Desired and Observed Average Initial Lung Burdens of $147 \mathrm{Pm}$ and/or $238 \mathrm{pu}$ Inhaled in Fused Aluminosilicate Particles by Rats

3.2 Lung Retention Functions for Retention of $238 \mathrm{Pu}$ or $147 \mathrm{Pm}$ in the Lung of F344/Crl Rats

3.3 Dose Accumulation Functions for Calculating Cumulative Rads per nCi/g-Lung of $238 \mathrm{pu}$ or Per $\mu \mathrm{Ci} / \mathrm{g}$-Lung of $147 \mathrm{Pm}$ Initially Deposited in the Lung (ILB) as a Function of the Time (t) in Days After Inhalation Exposure of F344/Crl Rats

3.4 Expected and observed Deaths From Radiation Pneumonitis and Pulmonary Fibrosis Within 1.5 Years After Inhalation Exposure of $\mathrm{F} 344 / \mathrm{Cr} 1$ Rats to Mixtures of $238 \mathrm{Pu}$ and $147 \mathrm{Pm}$ Inhaled in Fused Aluminosilicate Particles

3.5 Blood Lymphocyte Counts After Inhalation Exposure of Rats of $238 \mathrm{Pu}_{\mathrm{u}}+147 \mathrm{Pm}$ Inhaled in Fused Aluminosilicate Particles

3.6 Predicted and Observed Cases of Respiratory Functional Morbidity Among F344/Crl Rats After Combined Alpha and Beta Irradiation of the Lung From Inhaled $147 \mathrm{Pm}$ and $238 \mathrm{Pu}$ in Fused Aluminosilicate Particles

3.7 Median Lethal Lung Burdens for Death From Radiation Pneumonitis and Pulmonary Fibrosis and Median Effective Lung Burdens for Respiratory Morbidity After Inhalation Exposure of F344/Crl Rts to $238 \mathrm{Pu}$ or $147 \mathrm{Pm}$ Inhaled in Fused Aluminosilicate Particles

3.8 Median Lethal 1.5 Year Radiation Doses to the Lung for Death Within 1.5 Years From Radiation Pneumonitis and Pulmonary Fibrosis and Median Effective Doses for Respiratory Morbidity at 1.5 Years After Inhalation Exposure of $\mathrm{F} 344 / \mathrm{Cr}$ Rats to $138 \mathrm{Pu}$ or $147 \mathrm{Pm}$ Inhaled in Fused Aluminosilicate Particles 
Research was supported by the Nuclear Regulatory Commission under an interagency agreement with the Department of Energy under Contract Number DE-AC04-76EV01013 and carried out in animal care facilities fully accredited by the American Association for Accreditation of Laboratory Animal Care. Many of the staff of the Inhalation Toxicology Research Institute contributed to this research. The efforts of the animal care, aerosol preparation and exposure, radiochemistry, hematology, respiratory physiology, and histopathology personnel were gratefully appreciated. We are also grateful to the Word Processing personnel for excellent typing support and to others for their support and critical review of our research. 


\section{EXECUTIVE SUMMARY}

Although current radiobiological research is largely focused on carcinogenic and genetic effects, the casualties caused by the recent Chernobyl nuclear power plant accident in the Soviet Union reemphasized the importance of research on acute radiobiological effects. Recognizing this need years before the Chernobyl accident occurred, the Nuclear Regulatory Commission (NRC) sponsored research on acute and continuing effects of irradiation designed to develop improved radiobiological health-effects models. This report provides experimental and theoretical results on lethality and morbidity effects caused by combined chronic alpha and beta irradiation of the 7ung, based on research carried out at the Inhalation Toxicology Research Institute (ITRI).

Studying effects of combined alpha and beta irradiation of the lung is important because the transport of radioactive materials associated with the nuclear fuel cycle could result in the accidental or intentional (i.e., by sabotage) release of mixtures of alpha- and beta-emitting radionuclides into the environment. If airborne, the radionuclides could be inhaled by man and could lead to large radiation doses to the lung. A large radiation dose to the lung can cause radiation pneumonitis and pulmonary fibrosis (RPPF) and could prove fatal or lead to impaired pulmonary function for a survivor.

A hazard-function ( $H F$ ) model was developed at our Institute for predicting the frequency of death from RPPF after complex patterns of beta-gamma irradiation or after combined alpha and beta irradiation of the lung. Several experiments were conducted to validate the mortality model and to provide data to develop a similar model for pulmonary morbidity.

Results of four experiments using rats to test the mortality model for predicting acute effects of complex patterns of beta-gamma irradiation of the lung are in another report (NUREG/CR-5025, 1987). The experiment described in this report was carried out to validate the model for predicting death from RPPF after combined alpha and beta irradiation of the lung and to provide data for developing and validating a similar model for pulmonary morbidity.

Prediction of death from RPPF after combined alpha and beta irradiation of the lung is based on a hazard-function model expressed by the Weibull-type function

$$
\text { LETHALITY HAZARD }=\ln (2) \cdot X^{V} \text {, }
$$

where $V$ is a positive parameter that determines the shape of the dose-effect relationship. $x$ is the total alpha plus beta dose in ILB50 units. It is calculated by dividing the initial lung burden for the alpha emitter by the median lethal initial lung burden (ILB50) for the alpha emitter resulting in the alpha dose, $x_{a}$, in ILB50 units for the alpha emitter. A similar procedure is used to derive a similar dose for the beta emitter. $x_{b} . x$ is then equal to $x_{a}+x_{b}$.

Doses $x_{a}, x_{b}$. and $x$ can also be defined in terms of the cumulative radiation dose to the lung evaluated to a fixed time (e.g., 1.5 year dose). To do so, the median lethal radiation dose (D50) must be known for both the alpha and the beta emitter, evaluated to the same fixed time as the cumulative radiation dose.

The lethality risk is related to the lethality hazard by the expression

$$
\text { RISK }=1-\exp [- \text { HAZARD }] .
$$

The risk for pulmonary morbidity was estimated in a similar way. 
To validate the HF model for lethality and to develop and validate a similar model for morbidity, $395 \mathrm{~F} 344 / \mathrm{Cr}$ rats, approximately 15 weeks of age were exposed via inhalation to $238 \mathrm{pu}$ only, ${ }^{147} \mathrm{Pm}$ only, or mixtures of both, in insoluble fused aluminosilicate particles (FAP). Control animals were exposed to fused aluminosilicate particles only.

The alpha emitter selected for the study was $238 \mathrm{pu}$ because of its high specific activity. This made it possible to use the same FAP aerosol for both $238 p_{u}$ and $147 \mathrm{pm}$, as we11 as permitting the use of a single radioactive tag, in a single inhalation exposure, thus minimizing the variability in lung deposition of the radionuclides.

Lung tissue content of $238 \mathrm{Pu}$ and $147 \mathrm{Pm}$ was determined using both whole-body counting of a $169 \mathrm{Yb}$ gamma-emitting tag and radiochemical analyses of tissues from sacrificed rats and those dying during the study. The radiochemical procedures included ashing, dissolution, and counting by liquid scintillation methods.

Biological endpoints monitored on all rats during the study were body weights, histological changes, and survival time. The probable cause of death was determined for each rat that died during the 1.5 year followup period. Respiratory function tests were performed on 117 survivors at 1.5 years after inhalation exposure.

For the $238 \mathrm{Pu}$-alpha irradiation of the 7 ung, the ILB50 for death within 1.5 years from RPPF was $123 \mathrm{nci} / \mathrm{g}$-lung, which corresponds to a cumulative 1.5 year radiation dose of $4500 \mathrm{rad}$ (45 Gy) to the lung. For $147 \mathrm{Pm}$-beta irradiation of the lung, the ILB 50 was $160 \mu \mathrm{Ci} / \mathrm{g}-1$ ung, which corresponded to a cumulative 1.5 year radiation dose of about 30,000 rad ( $300 \mathrm{~Gy}$ ) to the lung. The shape parameter, $V$, for lethality from RPPF was similar for alpha and beta irradiation of the lung with an average value of approximately 5.

After review of several respiratory parameters, four were selected and used to determine the prevalence of pulmonary functional morbidity. These parameters were vital capacity, quasistatic compliance, co-diffusing capacity per $\mathrm{kg}$ body weight, and slope of phase 3 of the single-breath $\mathrm{N}_{2}$ washout curve. Vital capacity reflected changes in lung volume; quasistatic lung compliance reflected changes in lung elasticity; the slope of phase 3 of the single-breath $\mathrm{N}_{2}$ washout reflected the uniformity of gas distribution; and carbon monoxide diffusing capacity per kg body weight reflected alveolar-capillary gas exchange efficiency. Individuals having abnormal values for 3 or more of these 4 functional parameters were judged to have pulmonary morbidity.

For the $238 \mathrm{pu}-\mathrm{a}$ lpha irradiation of the lung, the ILB 50 for pulmonary morbidity was 30 $\mathrm{nCi} / \mathrm{g}-\mathrm{lung}$. which corresponded to a 1.5 year cumulative radiation dose of about 1.100 rad (11 Gy) to the lung. For the $147 \mathrm{Pm}$-beta irradiation of the $1 \mathrm{ung}$, the ILB 50 was $40 \mu \mathrm{Ci} / \mathrm{g}-1 \mathrm{ung}$, which corresponded to a 1.5 year cumulative radiation dose of about 7,500 rad (75 Gy) to the lung. The shape parameter. $V$, was assumed to be the same for both morbidity and lethality. A value of 5 was therefore also used for morbidity.

The results indicate that the same shape parameter can be used for alpha and beta irradiation of the lung and for mortality and morbidity. However, about four times as much dose is required for 1.5-year lethality from RPPF as is required for morbidity.

After adjusting for competing modes of death, 80 rats were judged at risk for death from RPPF after combined alpha and beta irradiation of the lung. Of these, 43 deaths were expected and 54 were observed. Also, for rats receiving combined alpha and beta irradiation of the lung, 21 out of 24 surviving rats were expected to have pulmonary functional morbidity while 22 cases were observed. The results indicate that the hazard-function mortality and hazard-function morbidity models for combined alpha and beta irradiation of the lung should be adequate for reactor accident risk assessment. 
The transport of radioactive materials associated with the nuclear fuel cycle could result in accidental or intentional (i.e., by sabotage) release of mixtures of alpha- and beta-emitting radionuclides into the environment. If released, the radioactive substances could become airborne and be inhaled by people leading to irradiation of critical body organs. When radionuclides are inhaled in an insoluble form, the lung is the main organ at risk. Small doses (hundreds of rad) to the lung may result in lung cancer, while large doses (thousands of rad) may result in other morbidity as well as death from radiation pneumonitis and pulmonary fibrosis (RPPF).

The experiment described in this report is the last of a series of inhalation-exposure experiments carried out at the Inhalation Toxicology Research Institute (ITRI) for the Nuclear Regulatory Commission (NRC) to validate an acute mortality model (Scott et al., 1984, 1986). The model was developed for predicting death from RPPF after inhalation exposure of a population to mixtures of beta emitting or mixtures of alpha- and beta-emitting radionuclides. The series of experiments was to also provide morbidity data for developing a similar model to predict morbidity from similar exposures.

The experiment described in this report was carried out to determine if the mortality model adequately predicts lethality from RPPF after combined alpha and beta irradiation of the lung from radionuclides deposited via inhalation. The experiment also provided pulmonary function, body weight, and hematology data to use in an exploratory analys is for morbidity.

Another report (NUREG/CR-5025, 1987) decribes results of inhalation exposure experiments carried out to (1) determine the affect of beta energy on the risk of death from RPPF and (2) to validate model predictions of acute lethalitiy from RPPF after internal exposure of the lung to complex patterns of low linear energy transfer (LET) radiation from beta-emitting radionuclides deposited in the lung. 


\subsection{Anima7s}

Male and female $F 344 / C r l$ rats were obtained from the Lovelace ITRI breeding colony for use in the study. The colony is free of known rat respiratory pathogens and is tested serologically every three months. The rats were $15 \pm 2$ weeks of age at exposure.

\subsection{Housing of Animals}

Before the rats were exposed, each was given a unique ear tag for identification. Rats of each gender were weighed and housed separately (two per polycarbonate cage). The room housing the rats was maintained at 20 to $22^{\circ} \mathrm{F}$. The relative humidity was maintained at 20 to $50 \%$. 12-hour-on 12-hour-off light cycle was used. Rats were fed Lab Blox (Allied Mills, Chicago, IL) and given water ad libitum.

\subsection{Experimental Design}

Equal numbers of both genders were randomized by body weight into exposure groups as indicated in Table 2.1. Randomization into mortality and hematology groups was constrained such that average body weights were similar over all exposure concentrations and groups for a given gender. Exposure levels $L_{01}$ and $L_{50}$ were based on concentrations intended to produce about $1 \%$ and 50\% lethality, respectively, from RPPF, for exposure to the alpha-emitter 238 Pu or beta-emitter $147 \mathrm{Pm}$ only. A gamma-emitting label. 169 $\mathrm{Yb}$, was incorporated into each of the FAP aerosols containing $147 \mathrm{Pm}$ and for $238 \mathrm{pu}$ to make it possible to estimate the initial lung burdens of these latter two radionuclides by whole-body counting. A uniform distribution of the initial lung burden (ILB) was assumed for each exposure group. Thirty-six rats were included in each of 9 exposure categories ( $L_{01}, L_{50}$, for $238 \mathrm{Pu}$ or $147 \mathrm{Pm}$, and combinations of both in the same particle) as indicated in Table 2.1. For example, 36 rats were exposed to the $L_{01}$ (alpha) $+L_{01}$ (beta) combination.

Table 2.1

238pu-Alpha + $147 \mathrm{Pm}-8 \mathrm{peta}$ Study Design and 1.5-Year

Survivors Among F344/Crl Rats Expressed by Exposure Level

\begin{tabular}{|c|c|c|c|c|c|c|}
\hline \multirow{3}{*}{$\frac{\left(^{\left.147_{\mathrm{Pm}}\right)}\right.}{L_{00}}$} & \multicolumn{6}{|c|}{ Alphas $\left({ }^{238} \mathrm{Pu}\right)$} \\
\hline & \multicolumn{2}{|c|}{$\mathrm{L}_{00}$} & \multicolumn{3}{|c|}{$\mathrm{L}_{01}$} & \multirow{3}{*}{$\begin{array}{c}\mathrm{L}_{50} \\
\text { Mortality } \\
\text { (AI) }\end{array}$} \\
\hline & Mortality & Hematology & Mortality & & & \\
\hline & $(C)^{\star}$ & (C) & $(A 2)$ & & & \\
\hline & $3 / 36$ & $0 / 8$ & $12 / 36$ & & & $28 / 36$ \\
\hline \multirow[t]{3}{*}{$\mathrm{L}_{01}$} & Mortality & & Mortality & Sacrifice & Hematology & Mortality \\
\hline & (B2) & & $(\mathrm{AB} 4)$ & (AB5) & (AB5) & $(A B 3)$ \\
\hline & $3 / 36$ & & $21 / 36$ & $50 / 50$ & $9 / 22$ & $35 / 36$ \\
\hline \multirow[t]{3}{*}{$L_{50}$} & Mortality & & Mortality & & & Mortality \\
\hline & (B1) & & (AB2) & & & $(A B 1)$ \\
\hline & $18 / 36$ & & $19 / 36$ & & & $35 / 35$ \\
\hline
\end{tabular}

\footnotetext{
*Items within parentheses represent experimental group designation. Ratios represent number dead at 1.5 years over number exposed. A hematology group (C1) of size 8 at $L_{00}+L_{00}$ level was added after initiation of the study. The hematology group at $\mathrm{L}_{01}+\mathrm{L}_{01}$ level was taken from animals initially assigned to the sacrifice study. One rat at $L_{50}+L_{50}$ level died at time of exposure. $L_{01}$ was intended to be a $1 \%$ affected leve1. L50 was intended to be a $50 \%$ affected level. L00 represents control exposure to nonradioactive fused aluminosilicate particles.
} 
Fifty additional rats were assigned to the $L_{01}$ (alpha) + $L_{01}$ (beta) exposure leve 1 to be sacrificed 6 at a time ( 3 of each gender) at $0,4,14,30,60,90,120$ and 150 days after inhalation exposure to provide needed dosimetry information. The remaining two were used as backups.

Eight rats were added to the $L_{00}$ (control) level and 22 to the $L_{01}$ (alpha) $+L_{01}$ (beta) level to provide hematological data at $7,14,30,60,90,180,365$ and 540 days after exposure. The eight control rats were not sham exposed.

\subsection{Biological Measurements}

Biological endpoints monitored on all rats during the study were body weight, histologic changes and survival time. Body weights were measured before exposure and at monthly intervals to 1.5 years after exposure. Surviving animals were observed twice per day for the 1.5-year observation period. Those moribund or critically 111 were euthanized. After death, all animals were examined for gross lesions. The lungs were weighed and fixed in $10 \%$ neutral buffered formalin, embedded in paraffin, sectioned at 5 microns and stained with hematoxylin and eosin for histologic evaluation. The probable cause of death was determined for each animal that died during the study.

Respiratory-function tests were performed on 117 (60 males and 57 females) survivors at 1.5 years after inhalation exposure using previously reported techniques (Harkema et al.. 1982). The distribution of these survivors among exposure concentrations is shown in Table 2.2. Measurements by plethysmography during halothane anethesia included 35 parameters for breathing patterns, lung volumes, lung mechanics, gas distribution, co diffusing capacity and forced exhalation. Data for all respiratory function parameters were reviewed, then a limited number of parameters reflecting key facets of function were selected for detailed analysis. Vital capacity reflected changes in lung volume, quasistatic lung compliance reflected changes in lung elasticity, the slope of phase 3 of the single-breath $\mathrm{N}_{2}$ washout reflected the uniformity of gas distribution, and carbon

Table 2.2

Survivors That Were Subjected to Pulmonary Function Testing at 1.5 Years

After Inhalation Exposure

\begin{tabular}{|c|c|c|c|c|c|c|}
\hline \multirow{3}{*}{$\begin{array}{c}\text { Beta } \\
\text { Exposure } \\
\text { Level }\end{array}$} & \multicolumn{6}{|c|}{ Alpha Exposure Level } \\
\hline & \multicolumn{2}{|c|}{${ }^{\mathrm{L}} 00$} & \multicolumn{2}{|c|}{${ }^{{ }}{ }_{01}$} & \multicolumn{2}{|c|}{$L_{50}$} \\
\hline & Male & Fema le & Ma le & Fema le & Male & Female \\
\hline Loo & 10 & 10 & 10 & 10 & 10 & 5 \\
\hline$L_{01}$ & 6 & 10 & 10 & 4 & -- & -- \\
\hline$L_{50}$ & 8 & 5 & 6 & 13 & -- & -- \\
\hline
\end{tabular}

Total males $=60$

Total females $=57$

Grand total $=117$ 
monoxide diffusing capacity per $\mathrm{kg}$ body weight reflected alveolar-capillary gas exchange efficiency.

Hematology was performed only on rats assigned to the hematology group (Table 2.1$)$. Measurements were taken at $7,14,30,60,90,180,360$ and 540 days after inhalation exposure. Blood was collected from the retrobulbar sinus in a capillary tube. Blood smears were made and the blood diluted in Unopettes ${ }^{\circ}$. Hematocrit, total red and white blood cells and white blood cell differential counts were determined.

\subsection{Aerosol Preparation and Generation}

Suspensions for aerosol generation were prepared by cation exchange of $147 \mathrm{Pm}, 238 \mathrm{pu}$, or ${ }^{169} \mathrm{Yb}$ into montmorillonite clay. The $238 \mathrm{Pu}$ and $147 \mathrm{Pm}$ were incorporated into separate batches of montmorillonite clay suspended in water. Appropriate aliquots of each batch were mixed together to achieve the desired initial ratios of alpha to beta activity in the exposure aerosol. With this approach, the initial ratio of alpha to beta activity was fixed for each exposure aerosol but differed among them. Polydisperse aerosols were generated with a Lovelace nebulizer and heat treated by passing through a heating column at $1150^{\circ} \mathrm{C}$ with a flow rate of $21 \mathrm{pm}$. The $169 \mathrm{Yb}$ gammaemitting tag was incorporated into the particles in small amounts (Table 2.3) to allow determination of particle retention in the lung through total-body counting.

The $238 \mathrm{pu}$ was selected for this study because of its high specific activity. This made it possible to use the same fused aluminosilicate particle (FAP) aerosols for both $238 \mathrm{Pu}$ and $147 \mathrm{Pm}$, as well as permitting the use of a single radioactive tag in a single inhalation exposure, thus minimizing the variability in the lung deposition of the radionuclides. Two separate aerosols would have required two exposures (one for the alpha emitter and one for the beta-emitter) and would have led to larger variability in the initial lung deposition and in the initial alpha to beta activity ratio.

\subsection{Total-Body Counting}

Shielded NaI(TI) crystal counters were used to detect gamma radiation from the $169 \mathrm{Yb}$ radioactive tag. Each counting unit consisted of three $5 \mathrm{~cm}$ by $3 \mathrm{~cm}$ sodium iodide crystals with built-in photomultiplier tubes spaced $120^{\circ}$ apart around a centrally located sample holder. Detectors were shielded by $10 \mathrm{~cm}$ of lead.

\subsection{Determination of Lung Radioactivity Content}

Rat lung specimens were analyzed for $238 \mathrm{pu}$ and for $147 \mathrm{pm}$, as detailed below, after the $169 \mathrm{Yb}$ had decayed to nondetectable levels. The procedures used included ashing, dissolution, and counting by liquid scintillation methods (Keough and Powers, 1970). This was a double label procedure that required mathematical resolution of the sample content of $238 \mathrm{Pu}$ and $147 \mathrm{Pm}$. Quench correction was by the external standard, channels-ratio method.

Tissue samples awaiting analysis were stored in $10 \%$ neutral buffered formalin solution in glass vials. For analysis, each sample was transferred to a Pyrex beaker, oried in an oven, dry ashed in a muffle furnace, and wet ashed with $\mathrm{HNO}_{3}$ and $\mathrm{H}_{2} \mathrm{O}_{2}$ to destroy the organic matrix. The resulting sample was redissolved in $100 \mathrm{ml}$ of $2 \mathrm{M} \mathrm{HNO}_{3}$. A $5 \mathrm{ml}$ aliquot of the clear, colorless solution was transferred to a liquid scintillation counting vial. Fifteen ml of Ready-Solv EP liquid scintillation cocktail (Beckman Instruments) was added to the vial. A one-day period was allowed between preparation of a sample and actual counting to allow the sample to stabilize chemically.

Quench correction standards were prepared for $238 \mathrm{Pu}$ and $147 \mathrm{Pm}$. These standards were necessary for quench correction and mathematical resolution of the $238 \mathrm{pu}_{\mathrm{u}}$ and $147 \mathrm{Pm}$ activity content in the rat tissues. There were 5 quench correction standards for $147 \mathrm{pm}, 5 \mathrm{for} 238 \mathrm{Pm}$, and 5 for standards that contained both $238 \mathrm{Pu}$ and $147 \mathrm{Pm}$. Five standards were used to provide a range of quenching that covered the anticipated range for the lung tissue samples. The degree of 
Table 2.3

Aerosol Concentrations, Aerosol Size, Exposure Run Time and

Initial Radionuclide to $169 \mathrm{Yb}$ Activity Ratios by Experiment Number

\begin{tabular}{|c|c|c|c|c|c|c|c|c|c|c|c|}
\hline \multirow[b]{2}{*}{$\begin{array}{c}\text { Experiment } \\
\text { Group } \\
\end{array}$} & \multicolumn{3}{|c|}{ Aerosol Concentration } & \multicolumn{2}{|c|}{ Aerosol Size* } & \multicolumn{2}{|c|}{${ }^{169} \mathrm{Yb}$ to Nuclide Ratio } & \multicolumn{3}{|c|}{ Predicted ILB's } & \multirow{2}{*}{$\begin{array}{l}\text { Run } \\
\text { Time } \\
\text { (min) }\end{array}$} \\
\hline & $\begin{array}{r}169 \mathrm{Yb} \\
(\mathrm{nCi} / 1) \\
\end{array}$ & $\begin{array}{r}238 \mathrm{pu} \\
(\mathrm{nCi} / 1) \\
\end{array}$ & $\begin{array}{r}147 \mathrm{Pm} \\
(\mu \mathrm{Ci} / 1) \\
\end{array}$ & $\begin{array}{l}\text { AMAD } \\
(\mu \mathrm{m}) \\
\end{array}$ & $\sigma_{\mathrm{g}}$ & $238 \mathrm{Pu}$ & $147 \mathrm{Pm}$ & $\begin{array}{l}{ }^{169} \mathrm{Yb} \\
(\mathrm{nCi})\end{array}$ & $\begin{array}{l}238 \mathrm{pu} \\
(\mathrm{nCi}) \\
\end{array}$ & $\begin{array}{l}147 \mathrm{Pm} \\
(\mu \mathrm{Ci})\end{array}$ & \\
\hline Al & 772 & 550 & $\mathbf{0}$ & 1.60 & 1.50 & 2.59 & NA & 320 & 230 & 0 & 35 \\
\hline A2 & 775 & 71.4 & 0 & 1.70 & 1.59 & 9.56 & NA & 420 & 40 & 0 & 60 \\
\hline 81 & 621 & NA & 132 & 1.42 & 1.77 & NA & 0.0047 & 447 & NA & 100 & 60 \\
\hline B2 & 943 & NA & 73 & 1.44 & 2.2 & MA & 0.013 & 475 & MA & 40 & 42 \\
\hline$A B 1$ & 661 & 248 & 107 & 1.40 & 1.50 & 2.67 & 0.0062 & 560 & 210 & 90 & 70 \\
\hline$A B 2$ & 622 & 72 & 114 & 1.27 & 1.6 & 12.3 & 0.0245 & 450 & 50 & 90 & 60 \\
\hline AB3 & 541 & 294 & 29 & 1.42 & 1.56 & 1.93 & 0.019 & 380 & 210 & 20 & 59 \\
\hline$A B 4$ & 429 & 45.4 & 18.1 & 1.45 & 1.61 & 11.2 & 0.0237 & 360 & 40 & 15 & 70 \\
\hline AB5 & 387 & 44 & 23.1 & 1.49 & 1.58 & 9.33 & 0.0167 & 380 & 50 & 20 & 60 \\
\hline
\end{tabular}

*AMAD represents activity median aerodynamic diameter. og represents the geometric standard deviation.

NA = not applicable. 
quenching was controlled by the amount of $\mathrm{HNO}_{3}$ in the vials. Techniques used for preparation of quenching correction standards were identical to those for preparation of samples. A new series of standards was prepared for each batch of rat tissue.

Samples were counted by liquid scintillation for 20 minutes. The $238 \mathrm{Pu}$ and $147 \mathrm{Pm}$ activities were counted in two channels (indicated here as $A$ and $B$ ) of the liquid scintillation counter. The efficiencies of counting $147 \mathrm{Pm}$ and $238 \mathrm{Pu}$ in Channel $A$ were indicated by $E_{11}$ and $E_{21}$, respectively. For Channel $B$ they were indicated by $E_{12}$ and $E_{22}$, respectively. Sample gross counts in channels $A$ and $B$ were corrected for background by counting blanks and obtaining net counts per minute $(\mathrm{cpm})$. Net $\mathrm{cpm}$ in channels $A$ and $B$ were represented $\mathrm{by}_{\mathrm{C}} \mathrm{CPM_{1 }}$ and $\mathrm{CPM} \mathrm{M}_{2}$, respectively. The counting efficiencies were functions of the external standard channels ratio. Curves were prepared relating counting efficiency to the external standard channels ratio for each radionuclide. Total disintegrations per minute (DPM) for $147_{\mathrm{Pm}}$ and $238 \mathrm{Pu}$, represented by $\left.D P M\right]$ and $\mathrm{DPM}_{2}$, respectively, were calculated using

$$
\begin{aligned}
& D P M_{1}=\left[C P M_{1} E_{22}-C P M_{2} E_{21}\right] /\left[E_{11} E_{22}-E_{12} E_{21} E_{21}\right. \\
& D P M_{2}=\left[C P M_{2} E_{11}-C P M_{1} E_{12}\right] /\left[E_{11} E^{\star} E_{22}-E_{12} E_{21}\right]
\end{aligned}
$$

After calculating $O P M_{1}$ and $D P M_{2}$, the total $D P M$ for $238 P_{u}$ and ${ }^{147} P_{m}$ in lung was calculated by multiplying the results by 20 , since only $1 / 20$ of each sample was counted.

\subsection{Estimation of Initial Lung Burdens}

Initial lung burdens for $238 \mathrm{Pu}$ and $147 \mathrm{Pm}$ were estimated indirectly. First, the initial lung burden of $169 \mathrm{Yb}$ was estimated from total-body counts of $169 \mathrm{Yb}$ at early times (from 14 to 104 days after exposure). Most of the total-body activity from 14 to 104 days was assumed to be in the lung. A single-component exponential retention function was used to estimate the day 0 intercept for $169 \mathrm{Yb}$, the estimated initial lung burden. Additional total-body activity cleared at early times was excluded. The initial lung burdens of $238 \mathrm{pu}$ and $147 \mathrm{pm}$ were estimated for each animal indirectly by multiplying the initial lung burden of $167 y b$ by the respective initial activity ratios (238Pu to $169 \mathrm{Yb}$ and $147 \mathrm{Pm}$ to $169 \mathrm{Yb}$ activity ratios).

The aerosol concentrations of $238 \mathrm{Pu}, 147 \mathrm{Pm}$, and $169 \mathrm{Yb}$ were determined by analyzing filters taken during exposure and are given in Table 2.3. Radioactivity counts for 238pu were obtained using a ZnS scintillation technique; for $147 \mathrm{Pm}$ they were achieved using a $\mathrm{p}-10$ gas proportional counter technique; and for ${ }^{169} \mathrm{Yb}$ they were obtained using a NaI(T1) detector.

\subsection{Estimation of Doses to Lung}

Separate curves were developed for retention of $238 \mathrm{Pu}$ and $147 \mathrm{Pm}$ in the lung using initial lung burden estimates and results of radiochemical analysis on specific rats assigned to the study for dosimetry purposes (sacrifice group) and those that died or were euthanized when critically i11. Retention curves for lung were obtained by fitting two-component exponential functions to the radiochemistry data using SAS nonlinear regression software (SAS, 1982).

The cumulative radiation dose to the lung at death and the cumulative dose to a specified time (e.g.. I year after inhalation exposure) were evaluated by numerical integration over the dose rate pattern for each exposed individual. Numerical evaluation of dose was required because the lung weight changed with time as the animals grew. Instantaneous dose rates $D R(t)$ at any given time $t$ after inhalation exposure were given by

$$
O R(t)=51.2^{\star} E \star A(t) \star f / W(t), \operatorname{rad} / \text { day }
$$


where

$E=0.062 \mathrm{MeV}$ for $147 \mathrm{Pm}$

$E=5.5 \mathrm{MeV}$ for $238 \mathrm{pu}$

$A(t)=$ the activity retained at time $t$ which equals the product of the initial lung burden in $\mu \mathrm{C} i$ and the radionuclide-specific lung retention function

$f=$ fractional energy absorption in the lung; 0.97 for $147 \mathrm{Pm}$ betas and 1 for $238 \mathrm{Pu}$ alphas (Snipes, 1980)

$W(t)=$ lung weight in $g$ at $t$ days after inhalation exposure

$=0.0050 *[$ Initial body weight in $g+124 * G F(t)]$, females

$=0.0041^{*}[$ Initial body weight in $g+166 * G M(t)]$, males

where the empirical function $G F(t)$ and $G M(t)$ obtained from an earlier publication (NUREG/CR-5025, 1987) are given by

$$
G F(t)=1-\exp (-0.0169 * t 0.822)
$$

and

$$
G M(t)=1-\exp (-0.0133 * t 0.938) .
$$

This method of evaluating doses was based on the assumption that the lungs continue to grow in irradiated rats as they do in unirradiated controls. Cumulative radiation doses to the lung for $147 \mathrm{Pm}$ betas and $238 \mathrm{Pu}$ alphas were evaluated separately at 1, 14, 30, 90, 180, 200, 360, 540. 730 and 1096 days after exposure, for an initial lung burden of $1 \mu \mathrm{Ci} / \mathrm{g}-1$ ung for $147 \mathrm{Pm}$ and 1 $\mathrm{nCi} / \mathrm{g}-1$ ung for $238 \mathrm{Pu}$, using numerical integration with a FORTRAN program. The data obtained for the cumulative dose in rad were then fitted with a two-component exponential function of the form

$$
\begin{aligned}
& \text { Cumulative dose/unit activity/g-lung }= \\
& \left.C 1^{\star}\left[1-\exp (-B)^{\star} t\right)\right]+C 2^{\star}\left[1-\exp \left(-B 2^{\star} t\right)\right] \text {, }
\end{aligned}
$$

where the parameters $C 1, C 2, B 1$ and $B 2$ were positive and depended on the type of radiation. $A$ single set of parameters were determined from the data for exposure to $147 \mathrm{Pm}$ only; a single set was obtained for exposure to $238 \mathrm{pu}$ only, and a single set was obtained for exposure to mixtures of $147 \mathrm{Pm}$ and $238 \mathrm{Pu}$. The fitted curves for the cumulative dose per $\mu \mathrm{Ci} 147 \mathrm{Pm}$ per g-lung or per nCi ${ }^{238} \mathrm{pu}$ per g-lung were used to evaluate cumulative rads to the lung at any desired time including the dose to death. To make this evaluation, the cumulative rads per unit initial lung burden (in ${ }_{\mu C i} 147 \mathrm{pm}$ per g-lung or $\mathrm{nCi} 238 \mathrm{pu}$ per g-lung) at the time of interest were multiplied by the initial lung burden expressed in activity per gram of lung. 


\section{CHAPTER 3}

RESULTS

\subsection{Initial Activity, Biological Clearance and Retention of Radioactive Material in the Lung}

Aerosols were polydisperse in their size distribution. Activity median aerodynamic diameters (AMAD) and geometric standard deviations are given in Table 3.1 along with aerosol concentrations and exposure durations. The activity ratios of $147 \mathrm{Pm}$ to ${ }^{169} \mathrm{Yb}$ and $238 \mathrm{Pu}$ to $169 \mathrm{Yb}$ in Table 2.3 were used to estimate actual initial lung burdens from total body $169 \mathrm{Yb}$ counts. The desired and actual initial lung burdens (averages) are given, by exposure level, in Table 3.1 .

Table 3.1

Desired and Observed Average Initial Lung Burdens of $147 \mathrm{Pm}$ and/or $238 \mathrm{Pu}$

Inhaled in Fused Aluminosilicate Particles by Rats

\begin{tabular}{|c|c|c|c|c|c|c|c|}
\hline \multirow{3}{*}{$\begin{array}{c}{ }^{147} \mathrm{Pm} \\
\text { Exposure }\end{array}$} & \multirow[b]{3}{*}{ Category } & \multicolumn{6}{|c|}{${ }^{238} \mathrm{Pu}$ Exposure Leve 1} \\
\hline & & \multicolumn{2}{|c|}{$\mathrm{L}_{00}$} & \multicolumn{2}{|c|}{$\mathrm{L}_{01}$} & \multicolumn{2}{|c|}{$L_{50}$} \\
\hline & & $P m\langle\mu C i)$ & $\underline{P u}\langle n C i\rangle$ & $\underline{P m}(\mu C i)$ & $\underline{P u(n C i)}$ & $P m(\mu C i)$ & $\underline{P_{u}(n C i)}$ \\
\hline \multirow[t]{2}{*}{$\mathrm{L}_{00}$} & Desired & 0 & 0 & 0 & 40 & 0 & 180 \\
\hline & Observed & 0 & 0 & 0 & $24 \pm 6$ & 0 & $130 \pm 40$ \\
\hline \multirow[t]{2}{*}{$\mathrm{L}_{01}$} & Desired & 20 & 0 & 20 & 40 & 20 & 180 \\
\hline & Observed & $21 \pm 12$ & 0 & $14 \pm 5$ & $26 \pm 10$ & $13 \pm 4$ & $130 \pm 44$ \\
\hline \multirow[t]{2}{*}{$L_{50}$} & Desired & 100 & 0 & 100 & 40 & 100 & 180 \\
\hline & Observed & $57 \pm 20$ & 0 & $42 \pm 15$ & $26 \pm 10$ & $51 \pm 20$ & $120 \pm 40$ \\
\hline
\end{tabular}

Curves for retention of radioactivity in lung (lung-retention functions) that were obtained using two-component exponential functions are plotted in Figures 3.1 and 3.2 . Separate lung-retention functions for $147 \mathrm{Pm}$ retention were obtained for exposure to $147 \mathrm{Pm}$ alone and for exposure to $147 \mathrm{Pm}$ in combination with $238 \mathrm{pu}$ (mixture). The lung-retention functions are given in Table 3.2. Separate lung-retention functions were also obtained for 238pu retention for exposure to $238 \mathrm{Pu}$ alone and for exposure to $238 \mathrm{Pu}$ in combination with $147 \mathrm{Pm}$.

Table 3.2

Lung Retention Functions for Retention of $238 \mathrm{Pu}$ or $147 \mathrm{Pm}$ in the Lung of $\mathrm{F} 344 / \mathrm{Cr} 1$ Rats*

\begin{tabular}{|c|c|c|c|c|c|}
\hline \multirow{3}{*}{$\frac{\text { Radionuclide }}{238 \mathrm{Pu}}$} & \multirow{2}{*}{$\begin{array}{l}\text { Type of } \\
\text { Exposure }\end{array}$} & \multicolumn{4}{|c|}{ Retention Function Parameter } \\
\hline & & $\mathrm{Al}$ & B1 & & B2 \\
\hline & $238 \mathrm{pu}$ on $1 \mathrm{y}$ & $0.41 \pm 0.11$ & $0.028 \pm 0.022$ & 0.0027 & \pm 0.00036 \\
\hline $238 \mathrm{Pu}$ & $238 \mathrm{Pu}+147 \mathrm{Pm}$ & $0.69 \pm 0.074$ & $0.015 \pm 0.0033$ & 0.00094 & \pm 0.00045 \\
\hline $147 \mathrm{Pm}$ & $147 \mathrm{Pm}$ on $1 \mathrm{y}$ & $0.67 \pm 0.10$ & $0.15 \pm 0.033$ & 0.0036 & \pm 0.00059 \\
\hline $147 \mathrm{Pm}$ & $238 p u+147 \mathrm{Pm}$ & $0.54 \pm 0.023$ & $0.091 \pm 0.044$ & 0.0033 & \pm 0.00016 \\
\hline
\end{tabular}

* Retention function $\left.=A 1^{*} \exp \left[-B 1^{*} t\right]+(1-A 1) \exp \left[-B 2^{*} t\right]\right)$, where $t$ is in days. 


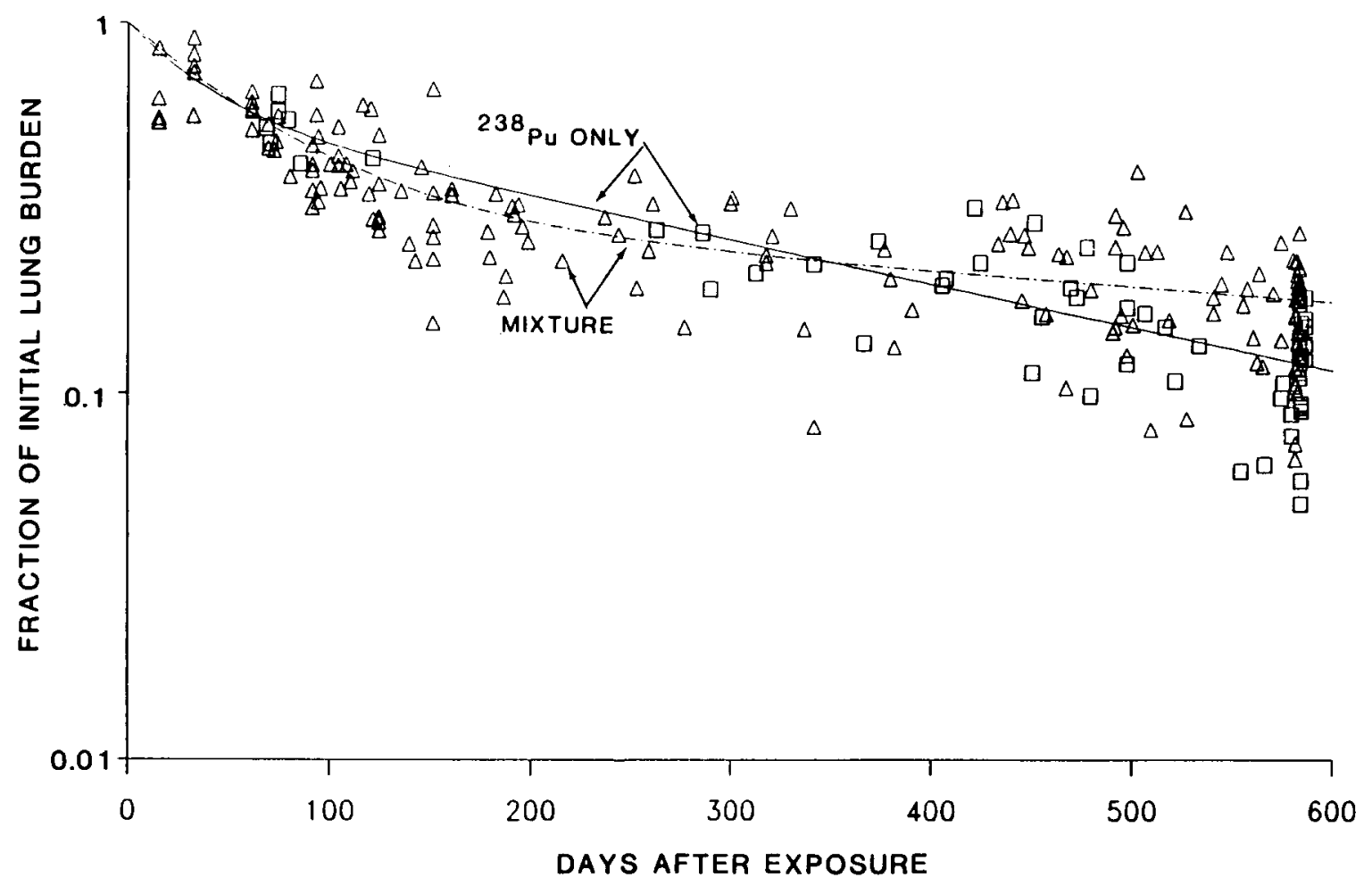

Figure 3.1 Pulmonary retention of $238 \mathrm{Pu}$ in $\mathrm{F} 344 / \mathrm{Cr} 1$ rats after (a) inhalation exposure to $238 \mathrm{pu}$ only, in fused aluminosilicate particles and after (b) inhalation exposure to mixtures of $238 \mathrm{Pu}+147 \mathrm{Pm}$ in the same fused aluminosilicate particle matrix.

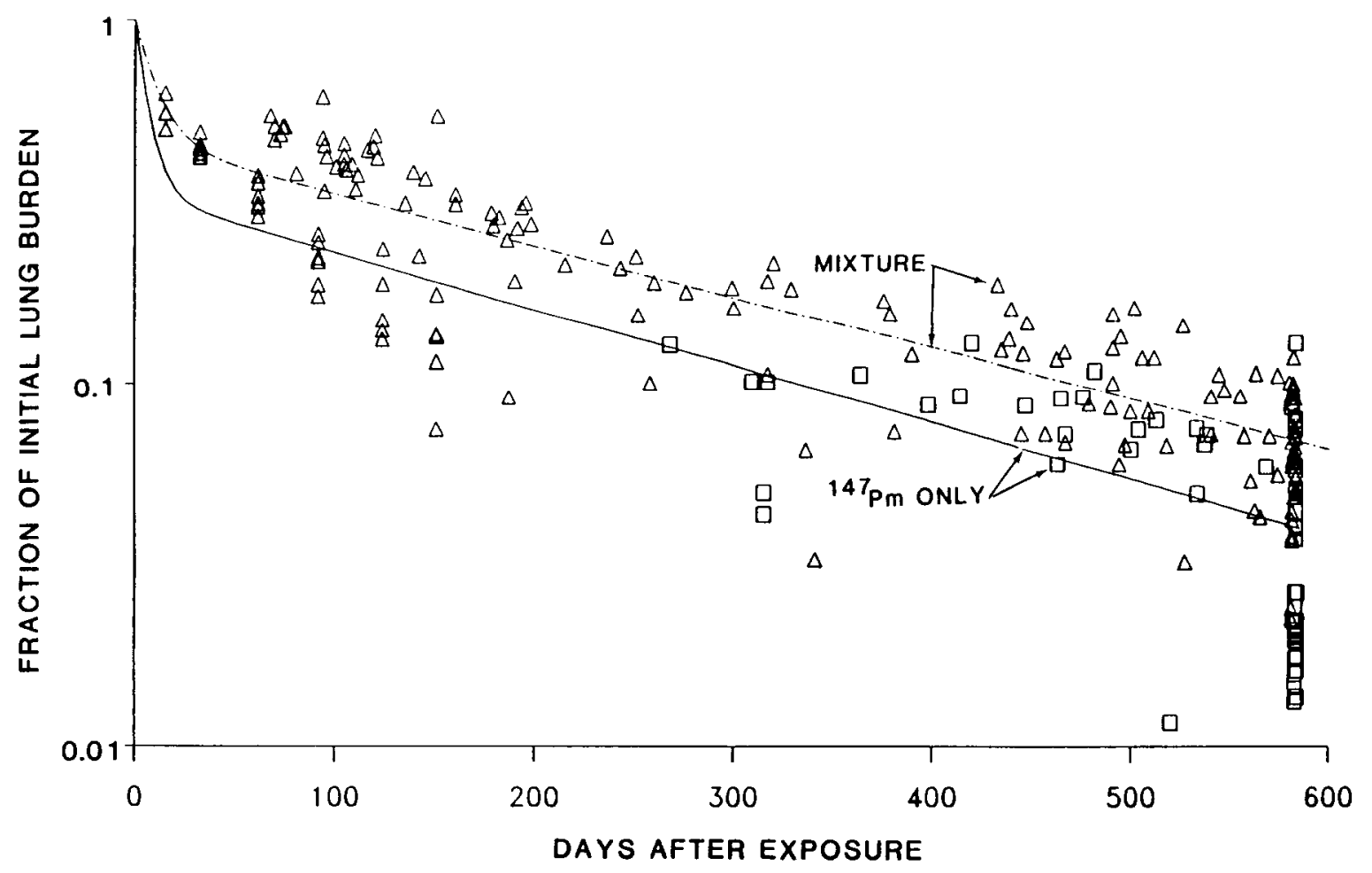

Figure 3.2 Pulmonary retention of $147 \mathrm{Pm}$ in $\mathrm{F} 344 / \mathrm{Cr}$ rats after (a) inhalation exposure to $147 \mathrm{Pm}$ only, in fused aluminosilicate particles and after (b) inhalation exposure to mixtures of $238 \mathrm{Pu}+147 \mathrm{Pm}$ in the same fused aluminosilicate particle matrix. 
Dose accumulation expressed as rads per $\mathrm{nCi} 238 \mathrm{Pu}$ per g-lung or rads per $\mu \mathrm{Ci} 147 \mathrm{Pm}$ per g-lung were first evaluated numerically by gender. Results obtained were essentially the same for both genders so that an average of both was obtained and fitted with a two-component exponential function. The fitted functions obtained are plotted in Figures 3.3 and 3.4 and are given in Table 3.3. These functions were used to calculate radiation doses to the lung to the desired times as described above.

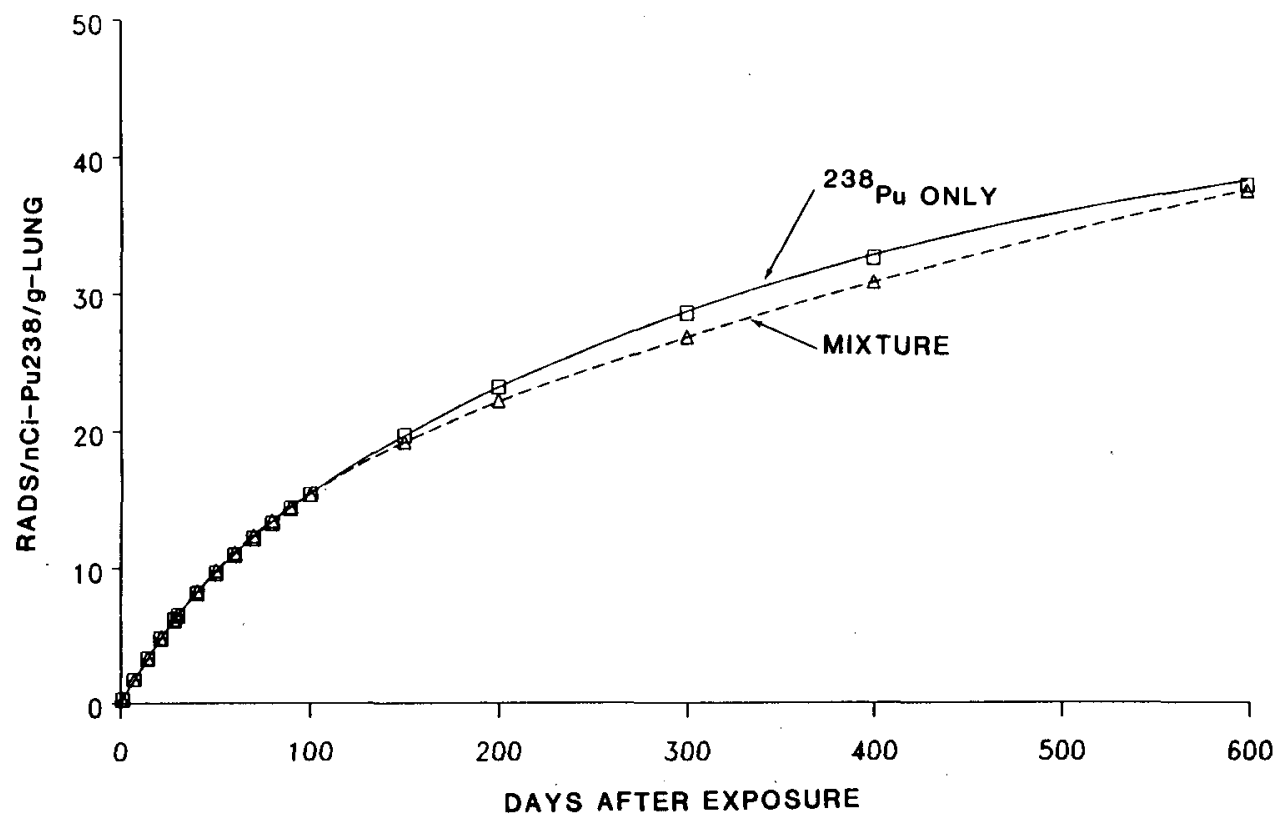

Figure 3.3 Fitted two-component exponential curves for calculating, as a function of time after inhalation exposure, rads per $\mathrm{nci} / \mathrm{g}-1 \mathrm{ung}$ due to $238 \mathrm{pu}$ initially deposited in the lung (ILB). Separate curves are provided for exposure to "238pu only" and for exposure to "238pu+147 Pm." To get cumulative rads to the lung at a specified time, multiply the value of the curve at that time by the initial lung burden for $238 \mathrm{Pu}$ in $\mathrm{nCi} / \mathrm{g}-$ lung.

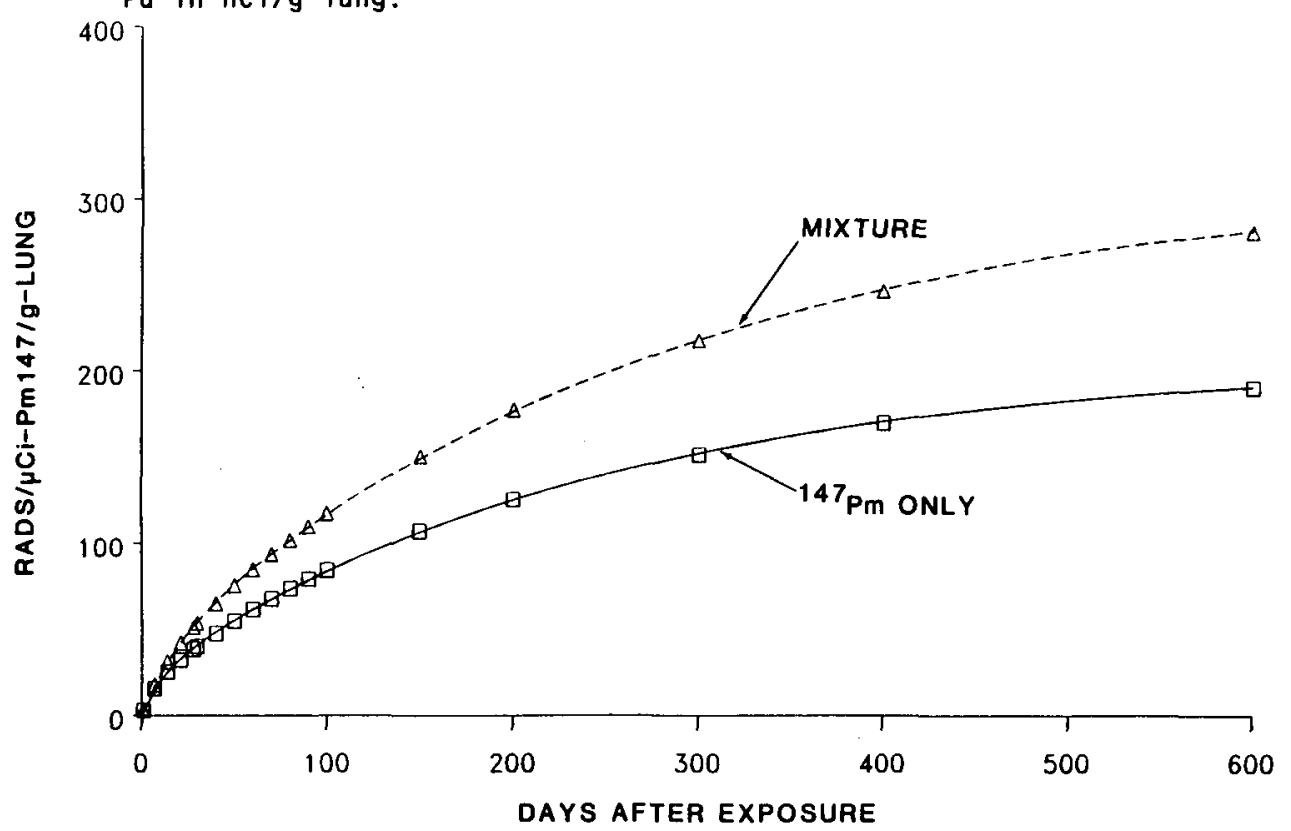

Figure 3.4 Fitted two-component exponential curves for calculating, as a function of time after inhalation exposure, rads per $\mu \mathrm{Ci} / \mathrm{g}-1$ ung due to $147 \mathrm{Pm}$ initially deposited in the lung (ILB). Separate curves are provided for exposure to "147 Pm only" and for exposure to "238 Pu $+147 \mathrm{Pm}$." To get cumulative rads to the lung at a specified time, multiply the value of the curve at that time by the initial lung burden for $147 \mathrm{Pm}$ in $\mu \mathrm{Ci} / \mathrm{g}-$ lung. 
Table 3.3

Dose Accumulation Functions for Calculating Cumulative Rads per $\mathrm{nCi} / \mathrm{g}-\mathrm{Lung}$ of $238 \mathrm{Pu}$ or per $\mu \mathrm{Ci} / \mathrm{g}$-Lung of $147 \mathrm{Pm}$ Initially Deposited in the Lung (ILB) as a Function of the Fime $(t)$ in Days After Inhalation Exposure of $\mathrm{F} 344 / \mathrm{Cr} 1$ Rats*

\begin{tabular}{|c|c|c|c|c|c|}
\hline \multirow[b]{2}{*}{ Radionuclide } & \multirow{2}{*}{$\begin{array}{r}\text { Type of } \\
\text { Exposure }\end{array}$} & \multicolumn{4}{|c|}{ Dose Accumulation Function Parameter } \\
\hline & & $\mathrm{Cl}$ & B) & $\mathrm{C} 2$ & 82 \\
\hline $238 \mathrm{pu}$ & $238 p u$ only & 6.10 & 0.0268 & 39.2 & 0.00285 \\
\hline $238 \mathrm{Pu}$ & $238 p u+147 p m$ & 12.0 & 0.0176 & 53.3 & 0.00109 \\
\hline $147 \mathrm{Pm}$ & $147 \mathrm{Pm}$ on $7 y$ & 20.7 & 0.0831 & 186 & 0.00411 \\
\hline $147 \mathrm{Pm}$ & $238 p_{u}+147 p m$ & 30.9 & 0.0540 & 283 & 0.00360 \\
\hline
\end{tabular}

$\star$ Dose in $\mathrm{rad}=C 1^{\star}\left(1-\exp \left[-B 1^{\star} t\right]\right)+C 2 \star\left(1-\exp \left[-B 2^{\star} t\right]\right)$.

\subsection{Mortality Distribution}

The fraction dying from all causes to about 1.5 years after inhalation exposure is shown in Figure 3.5 as a function of exposure level. After adjusting for spontaneous deaths, the results indicate synergistic effects of the alpha and beta radiations for mortality from all causes for three of the four combinations. Adjustments were made by assuming that radiation induced and spontaneous effects were independent. A pronounced synergistic effect was observed for the L01 (alpha) + $L_{01}$ (beta) combination. While the $L_{01}$ level beta exposure caused no radiation induced early deaths and the $L_{01}$ alpha level caused $27 \%$ lethality, a, combination of these two levels caused 54\% lethality (a11 based on adjusted results).

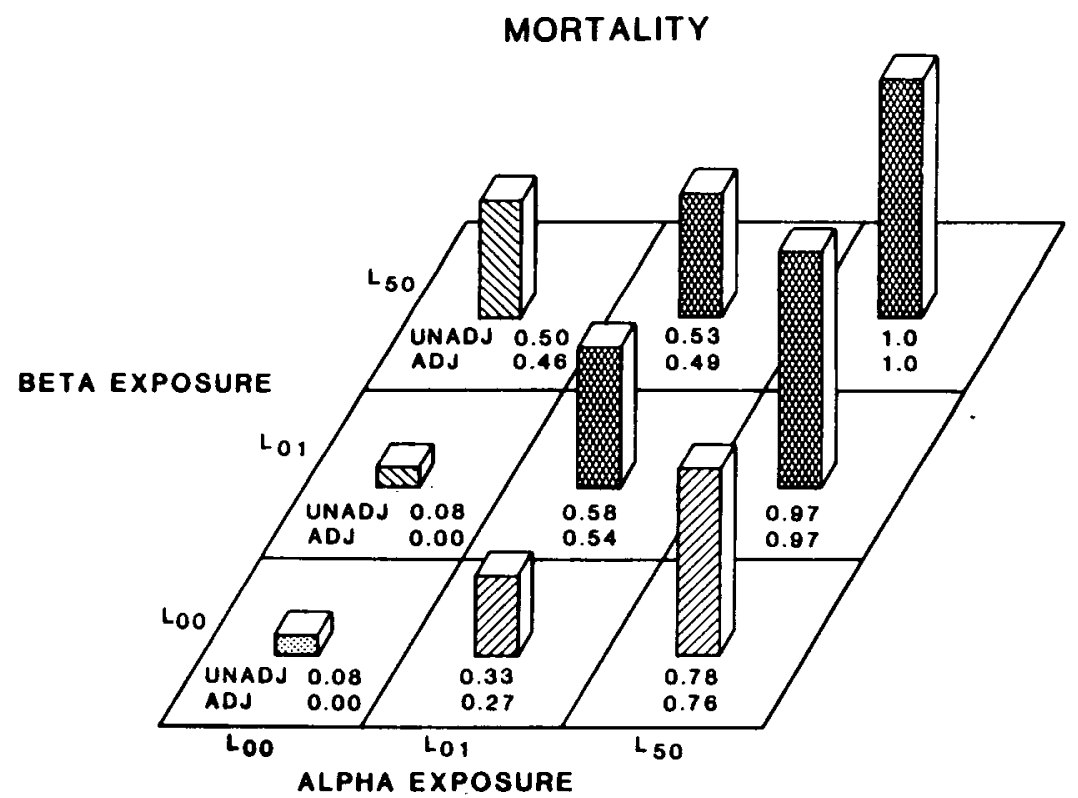

Figure 3.5 Unadjusted (UNADJ) distribution of 1.5 year mortality from all causes of death (except sacrifices) as a function of exposure level. Adjusted values (ADJ) to correct for spontaneous effects are also given and were calculated assuming independence of radiation-induced and nonradiation-induced effects. 
Histological examination of the rats that died revealed several causes of death, including RPPF and lung tumors. The major cause of death before 1.5 years was RPPF. It was characterized histologically by increased numbers of vacuolated alveolar macrophages and occasional neutrophils, alveolar hemosiderin, vasculitis and fine alveolar septal fibrosis. Thrombosis was also occasionally present. The cause of death was considered RPPF when these characteristics were found and there was no other obvious cause.

Survival times for death from all causes (except RPPF) vs the initial lung burdens of $238 \mathrm{pu}$ and $147 \mathrm{Pm}$ are given in Figure 3.6. Survival times for rats dying from RPPF are given in $F i g u r e$ 3.7 as a function of the initial lung burdens of $238 \mathrm{pu}_{\mathrm{u}}$ and $147 \mathrm{Pm}$. Note that survival time was inversely related to the total radionuclide activity deposited in the lung.

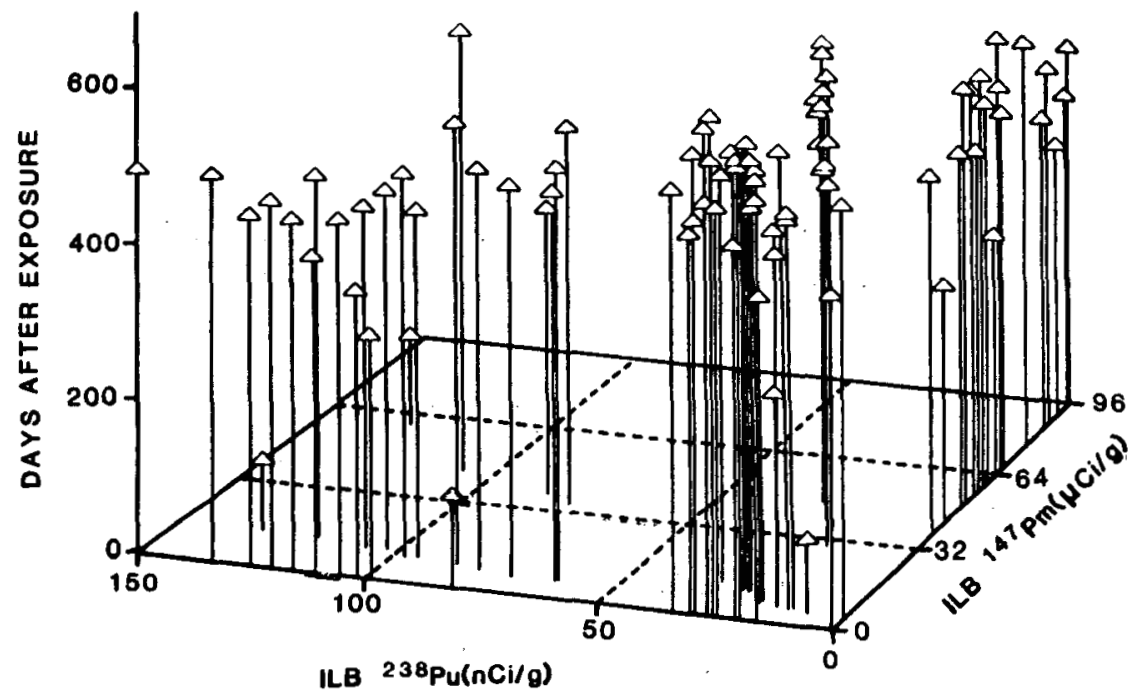

Figure 3.6 Survival time for death from all causes except radiation pneumonitis and pulmonary fibrosis as a function of the intial lung burden of $238 \mathrm{Pu}$ in $\mathrm{nCi} / \mathrm{g}-1 \mathrm{ung}$ and $147 \mathrm{Pm}$ in $\mu \mathrm{Ci} / \mathrm{g}-1$ ung. Time to euthanasia of morbid rats was used as estimates of time to death from radiation-induced and natural causes.

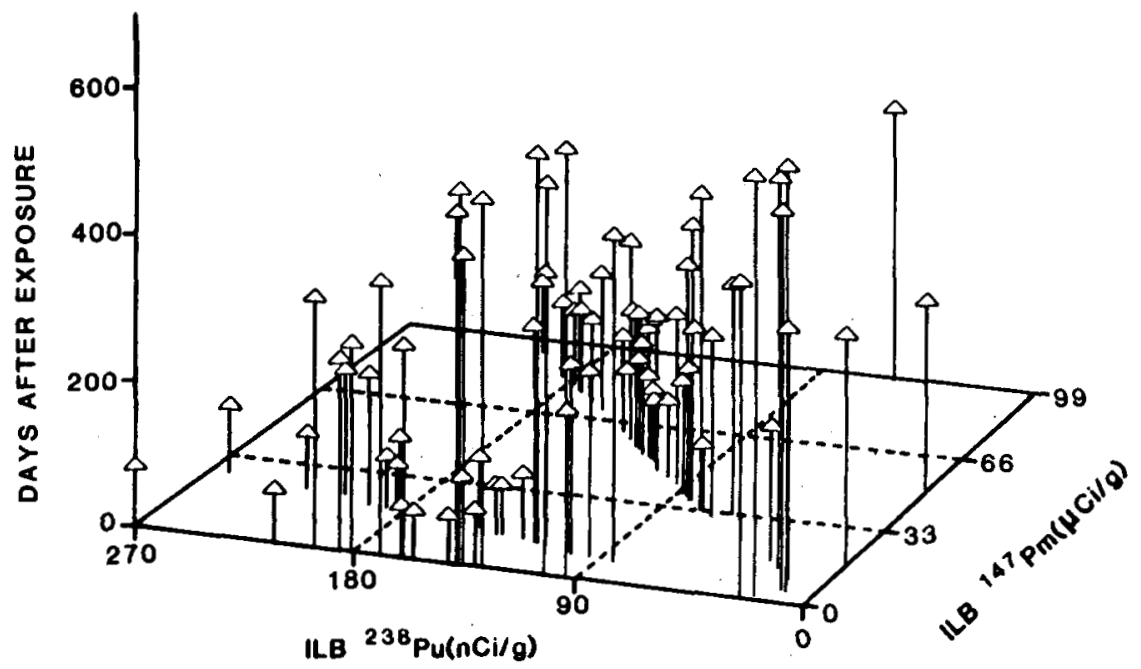

Figure 3.7 Survival time for death from radiation pneumonitis and pulmonary fibrosis. Time to euthanasia of morbid rats was used as an estimate of time to death from radiation induced causes. 
Risk estimators were developed for 1.5-year lethality from RPPF after inhalation exposure to only $238 \mathrm{Pu}$ and to only $147 \mathrm{Pm}$ when inhaled in fused aluminosilicate particles. Use of the maximum likelihood procedure allowed the analysis of individual data without having to form dose groups. This eliminated the systematic error associated with grouping of individuals that had different initial lung burdens. We have used a weibull type risk function for lethality that depends on the median lethal dose $D_{50}$ and shape parameter $V$ (Scott et al.. 1987). With this risk function model. the lethality hazard $H$ is related to the lethality risk $R$ by

$$
R=1-\exp (-H)
$$

where

$$
H=\ln (2) *\left[I L B / I L B_{50}\right]^{V} \text {. }
$$

The variable named ILB is the initial lung burden in $\mu \mathrm{Ci} / \mathrm{g}-1$ ung of $147_{\mathrm{Pm}}$ or $\mathrm{nCi} / \mathrm{g}-1 \mathrm{ung}$ of $238 \mathrm{Pu}$, and ILB50 is the median lethal initial lung burden. Once the ILB50 is known for $238 \mathrm{Pu}$ only or ${ }^{147} \mathrm{Pm}$ only. it can be used to calculate the median lethal dose $0_{50}$ in rads to any specified time (e.g.. I year). In this case, the ratio ILB/ILB50 in the above equation can be replaced by $0 / D_{50}$ where $D$ is the dose in rads to the time at which the $D_{50}$ dose is evaluated.

For $238 \mathrm{Pu}$, the median lethal initial lung burden and shape parameter obtained for death from RPPF within 1.5 years, were $123 \pm 7.5 \mathrm{nCi} / \mathrm{g}-1 \mathrm{ung}$ and $4.1 \pm 1.6$, respectively. For $147 \mathrm{Pm}$, the corresponding median lethal lung burden and shape parameter estimates were $160 \pm 190 \mu \mathrm{Ci} / \mathrm{g}-1 \mathrm{ung}$ and $5.4 \pm 0.9$, respectively. The large uncertainty in the median lethal initial lung burden for ${ }^{147} \mathrm{Pm}$ arises because intended initial lung burdens were not achieved. The rats were underexposed, leading to only one death attributed to RPPF after exposure to $147 \mathrm{Pm}$ only. Twenty-five deaths were attributed to other causes, primarily pulmonary tumors. The estimate of $160 \mu \mathrm{Ci} / \mathrm{g}-1 \mathrm{ung}$ for the median lethal initial lung burden was identical to that obtained in an earlier experiment where there were many deaths attributed to RPPF (NUREG/CR-5025, 1987).

An attempt was made to use the unimodal Weibull model to characterize dose-effect curves for 1-year lethality from all causes. However, because deaths from causes other than RPPF occurred at doses below the effective threshold for death from RPPF, satisfactory fits to the multimodal data could not be obtained using the unimodal model.

\subsection{Expected and Observed Deaths}

Based on the hazard function model for predicting the combined effects of high-LET alpha and low-LET beta irradiation of the lung, the lethality hazard for death from RPPF can be predicted in the following way. Divide the ${ }^{147} \mathrm{Pm}$ initial lung burden by the ILB 50 for ${ }^{147} \mathrm{Pm}$ to obtain the beta dose $x_{b}$ in units of the ILB50. Also divide the $238 \mathrm{Pu}$. initial lung burden by the ILB50 for $238 \mathrm{Pu}$ to obtain the alpha dose $x_{a}$ in units of the ILB50. Add $x_{a}$ and $x_{b}$ to obtain the total dose $x$ in units of the $D_{50}$. Next calculate the fraction. $F_{a}$ of the dose $x$ that is due to $x_{a}$, where

$$
F_{a}=x_{a} / x
$$

Also calculate the fraction $F_{b}$ of the dose $x$ that is due to $x_{b}$, where

$$
f_{b}=x_{b} / x .
$$


For exposure to the mixture, the shape parameter $V$ can be obtained using the weighted reciprocal relationship (Scott, 1987: Scott et al.. 1986)

$$
1 / V=F_{a} / V_{a}+F_{b} / V_{b}
$$

where $V_{a}$ and $V_{b}$ are the shape parameters for exposure to alphas only and betas only, respectively. The reciprocal relationship is needed only when $v_{a}$ and $v_{b}$ differ significantly. When $v_{a}$ and $v_{b}$ are approximately equal, $v$ can be calculated as the average of $v_{a}$ and $v_{b}$. This latter averaging procedure has been used here because $v_{a}$ and $v_{b}$ were found to be approximately the same. The reciprocal relationship is included for completeness.

Based on the hazard function model of predicting the combined effects of alpha and beta irradiation of the lung, the lethality hazard is given by

$$
H=\ln (2) \star x V
$$

Knowing the lethality hazard $H$, one can then calculate the individual risk of dying from RPPF using the relationship

$$
\text { Individual Risk }=1-\exp (-H) \text {. }
$$

Adding the individual risks over the dose distribution for the exposed sample of rats leads to the expected cases of deaths when all other competing risks are eliminated. We have used this method to predict the number of deaths from RPPF occurring within 1.5 years after inhalation exposure of $\mathrm{F} 344$ rats to mixtures of $238 \mathrm{Pu}$ and $147 \mathrm{Pm}$. All rats dying of other competing risks during the 1.5-year interval were excluded from the analysis. Only rats that died from RPPF or survived to 1.5 years were included. The expected and observed numbers of deaths are shown in Table 3.4 and are in good agreement. This indicates that the hazard-function method of predicting the combined lethal effects of alpha and beta irradiation of the lung should be adequate for use in reactor accident consequence modeling.

\subsection{Morbidity}

\subsubsection{Body Weight Changes}

A reduced body weight was observed only in rats that died from radiation-induced injury. Average body weights by exposure level are given in Figures 3.8-3.10 for 3,6 and 12 months after the inhalation exposure. Similar results were obtained at all other times that body weights were recorded. An exploratory analysis of the data revealed that a reduction in body weight mainly occurred in rats that accumulated lethal radiation doses.

\subsubsection{Hematology}

Hematological measurements were made repeatedly on the same males and females from the $L_{01}$ (alpha) + L01 (beta) level and on preselected controls assigned to the hematology group. No significant effects on the peripheral blood were observed. Data for the radiosensitive lymphocytes are given in Table 3.5 where $L_{c}$ and $L_{t}$ represent the average control and average test group [ $L_{01}$ (alpha) + $L_{01}$ (beta) level] counts at various times after exposure; $S L_{c}$ and $S L_{t}$ represent standard deviations for $L_{c}$ and $L_{t}$, respectively. The expression $100 L_{t} / L_{c}$ with standard deviation SD represents the average test counts expressed as a percentage of the average control value at the specified time. Based on an assumed normal distribution, no significant departure from control values could be demonstrated. None of the other hematological parameters was significantly different from control values. 
Table 3.4

Expected and Observed Deaths from Radiation Pneumonitis and Pulmonary Fibrosis

Within 1.5 Years After Inhalation Exposure of $F 344 / C r l$ Rats to

Mixtures of $238 \mathrm{pu}$ and $147 \mathrm{Pm}$ Inhaled in Fused Aluminosilicate Particles

\begin{tabular}{|c|c|c|c|c|c|}
\hline \multirow{3}{*}{$\begin{array}{l}\text { Experiment } \\
\text { Group } \\
\end{array}$} & \multicolumn{2}{|c|}{$\begin{array}{c}\text { Average Initial } \\
\text { Lung Burden } \\
\end{array}$} & $\begin{array}{l}\text { Risk } \\
\text { Set }\end{array}$ & \multirow[b]{2}{*}{ Expected } & \multirow[b]{2}{*}{ Observed } \\
\hline & $238 \mathrm{pu}$ & $147 \mathrm{Pm}$ & Size & & \\
\hline & $(n C i / g)$ & $(\mu \mathrm{Ci} / \mathrm{g})$ & $N^{\star}$ & Deaths ${ }^{\star \star}$ & Deaths \\
\hline$A B 1$ & $120 \pm 40$ & $51 \pm 20$ & 32 & $25 \pm 2.4$ & 32 \\
\hline $\mathrm{AB} 2$ & $26 \pm 10$ & $42 \pm 15$ & 18 & $1 \pm 1$ & 1 \\
\hline$A B 3$ & $130 \pm 44$ & $13 \pm 4$ & 22 & $17 \pm 2$ & 21 \\
\hline$A B 4$ & $26 \pm 10$ & $14 \pm 5$ & 8 & 0 & 0 \\
\hline
\end{tabular}

\footnotetext{
*After elimination of animals dying within 1.5 years from all causes other than radiation pneumonitis.

**Individual risk $=1-\operatorname{EXP}\left(-0.693 X^{5}\right)$

$X=X_{P M}+X_{P U}$

$X_{P M}=I L B P M(\mu C i / G-L U N G) / 160$

$X_{P U}=I L B P U(n C i / G-L U N G) / 123$

Average $\mathrm{risk}=$ (Sum of individual risks) $/ \mathrm{N}$

Variance $=N^{*}$ (Average risk) $(1$ - Average risk)

Expected deaths $=(\text { Risk set size })^{\star}($ Average risk)
} 
AVERAGE BODY WEIGHT: 3 MONTHS
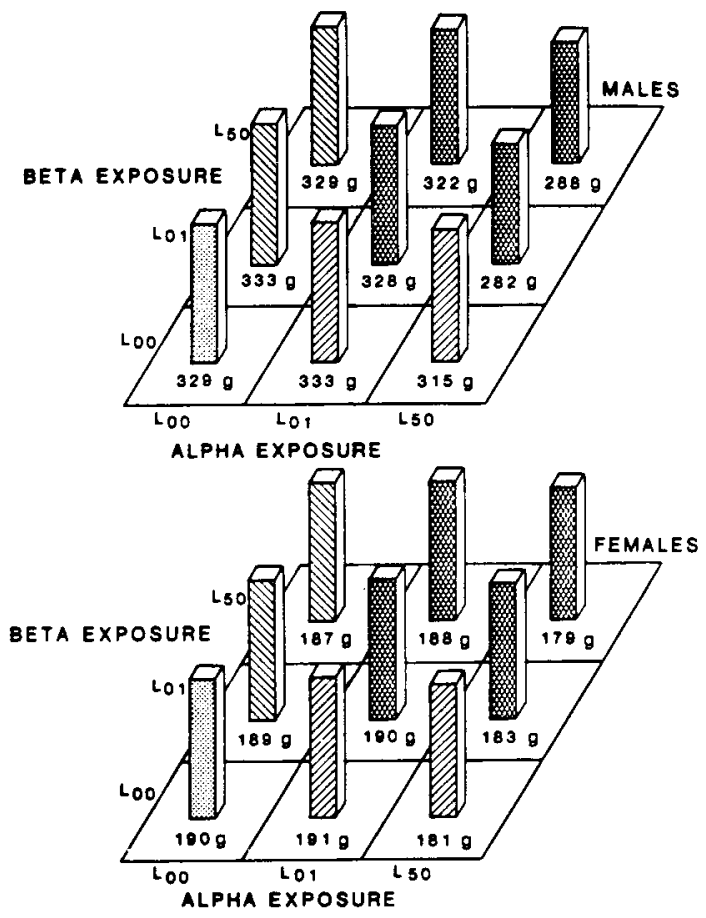

Figure 3.8. Average body weight in grams, as a function of the exposure level, evaluated at 3 months after inhalation exposure; (a) males, (b) females.
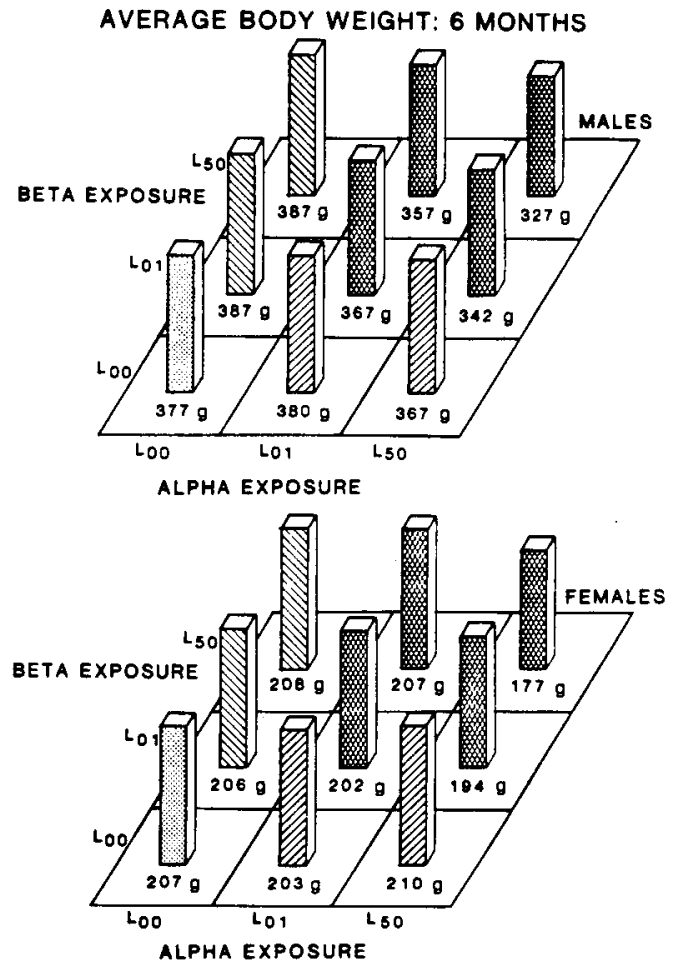

Figure 3.9. Average body weight in grams, as a function of exposure level, evaluated at 6 months after inhalation exposure; (a) males, (b) females.

AVERAGE BODY WEIGHT: 12 MONTHS
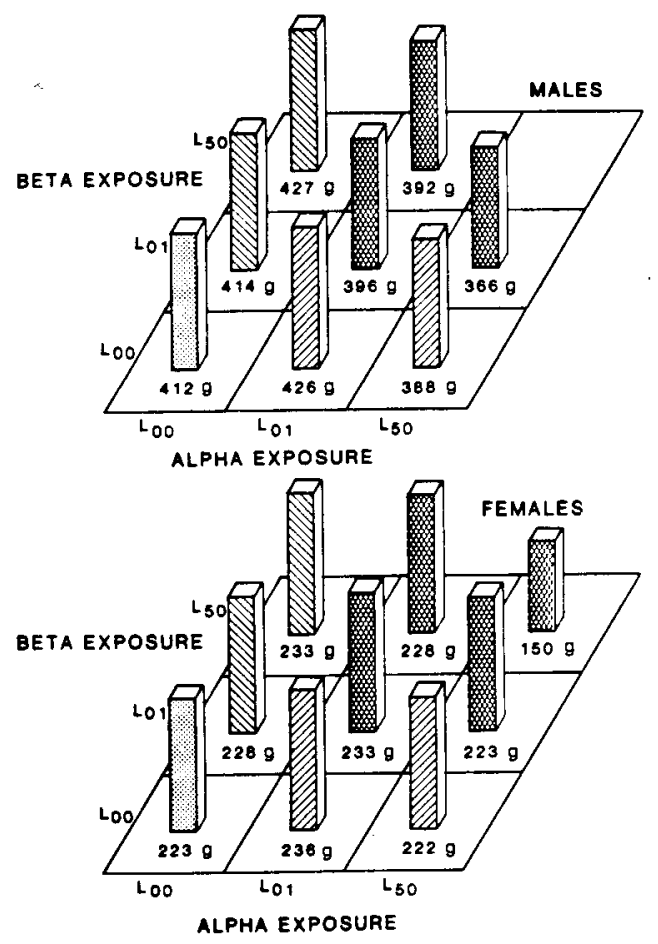

Figure 3.10 Average body weight in grams, as a function of exposure level, evaluated at 12 months after inhalation exposure; (a) males, (b) females. 
Table 3.5

B lood Lymphocyte Counts After Inhalation Exposure of Rats to $238 \mathrm{Pu}+147 \mathrm{Pm}$ Inhaled in Fused Aluminosilicate Particles*

\begin{tabular}{|c|c|c|c|c|c|c|}
\hline \multirow[b]{2}{*}{ DPE } & \multicolumn{2}{|c|}{ Controls } & \multicolumn{2}{|c|}{$L_{01}$ alpha $+L_{01}$ beta } & \multicolumn{2}{|c|}{$\begin{array}{c}\text { Average as Percent } \\
\text { of controls }\end{array}$} \\
\hline & $\begin{array}{c}\text { Average } \\
\left(\mathrm{L}_{\mathrm{C}}\right)\end{array}$ & $\begin{array}{c}\text { Standard } \\
\text { Deviation } \\
\left(\mathrm{SL}_{\mathrm{C}}\right) \\
\end{array}$ & $\begin{array}{c}\text { Average } \\
\left(L_{t}\right) \\
\end{array}$ & $\begin{array}{l}\text { Standard } \\
\text { Deviation } \\
\left(\mathrm{SL}_{\mathrm{t}}\right) \\
\end{array}$ & $\begin{array}{c}\text { Average } \\
\left(100 L_{t} / L_{c}\right)\end{array}$ & $\begin{array}{l}\text { Standard } \\
\text { Deviation } \\
\quad(\mathrm{SD})\end{array}$ \\
\hline 0 & -- & -- & -- & -- & 100 & -- \\
\hline 30 & 7009 & 1552 & 7088 & 2058 & 101 & 37 \\
\hline 60 & 7796 & 1516 & 9463 & 4322 & 121 & 60 \\
\hline 90 & 7485 & 2937 & 6850 & 1845 & 92 & 44 \\
\hline 120 & 7350 & 2462 & 7497 & 3601 & 102 & 60 \\
\hline 150 & 8800 & 4029 & 8328 & 3337 & 95 & 58 \\
\hline 180 & 5044 & 2451 & 5667 & 4913 & 112 & 112 \\
\hline 270 & 5203 & 1634 & 5618 & 3042 & 108 & 68 \\
\hline $360^{\star \star}$ & 3002 & 812 & 3272 & 974 & 109 & 44 \\
\hline
\end{tabular}

\footnotetext{
${ }^{*} \mathrm{~L}_{c}=$ control group average lymphocyte count $(\mathrm{ce} 11 \mathrm{~s} / \mathrm{cmm})$

$L_{t}=$ test group (D01 alpha +001 beta level) average lymphocyte counts (cells/cmm)

$100 L_{t} / L_{c}=$ average iymphocyte count for test group expressed as percent of average control value at specified time

$S L_{c}=$ standard deviation of $L_{c}$

$S L_{t}=$ standard deviation of $L_{t}$

$S D=$ standard deviation of $100 L_{t} / L_{c}$

DPE = days after exposure

** Lymphocyte counts as well as other hematological data had systematic error at 360 days. Data were multiplied by correction factor of 2 for sampling volume error correction to reduce systematic error. Systematic error was eliminated by taking ratio $L_{t} / L_{c}$.
}

\subsubsection{Respiratory Function}

It is shown in Figures $3.11-3.14$ that survivors 1.5 years after inhalation exposure had a reduction in vital capacity (Fig. 3.11), co diffusing capacity (Fig. 3.12), and quasistatic compliance (Fig. 3.13), and an increase in the slope of phase 3 of the single-breath nitrogen washout curve (Fig. 3.14). These changes reflected the presence of a restrictive lung disorder (smaller, stiffer lungs) with an uneven distribution of lesions (nonuniform gas distribution) and an impairment of gas exchange. The alterations are characteristic of RPPF from internally deposited alpha and beta-gamma emitters (Mauderly et al. 1980A, 1980B).

Pulmonary function data were quantified in the following way to develop risk parameters for estimating the prevalance of respiratory dysfunction resulting from irradiation of the lung. Each irradiated rat having a vital capacity measurement less than the 1ower $95 \%$ confidence interval for control values was judged to have a reduced lung volume. Each irradiated rat having a co diffusing capacity (normalized to $\mathrm{kg}$ body weight) less than the lower $95 \%$ confidence interval for controls was judged to have abnormal gas exchange in the lung. Each irradiated rat having a quasistatic compliance less than the lower $95 \%$ confidence interval for control values was judged to have stiffer than normal lungs. Each rat having a slope of phase 3 of the $\mathrm{N}_{2}$ washout curve greater than the upper $95 \%$ confidence interval for controls was judged to have an abnormal ventilation distribution in the lung. 
VITAL CAPACITY
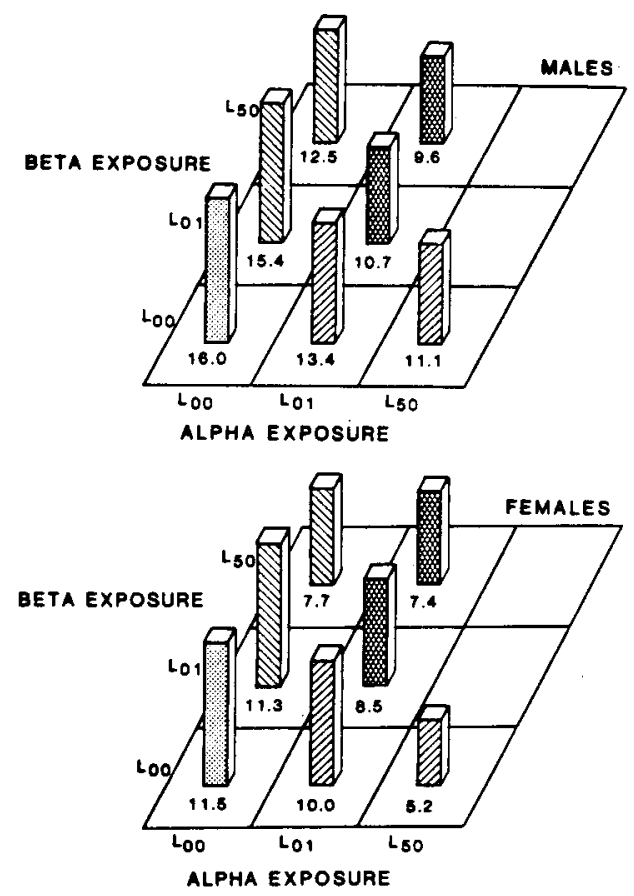

Figure 3.11. Average value for vital capacity in $\mathrm{ml}$, as a function of the exposure level. evaluated at 1.5 years after inhalation exposure; (a) males, (b) females.
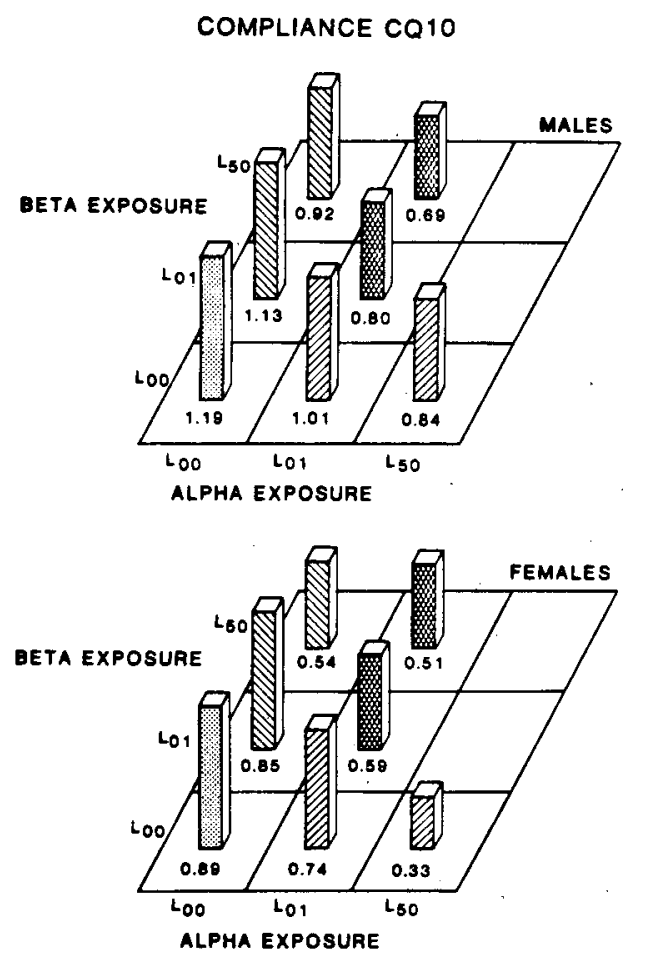

Figure 3.13. Average value for quasistatic compliance $(\mathrm{CQ10})$, in $\mathrm{ml} / \mathrm{CmH}_{2} \mathrm{O}$, as a function of the exposure level, at 1.5 years after inhalation exposure; (a) males, (b) females.
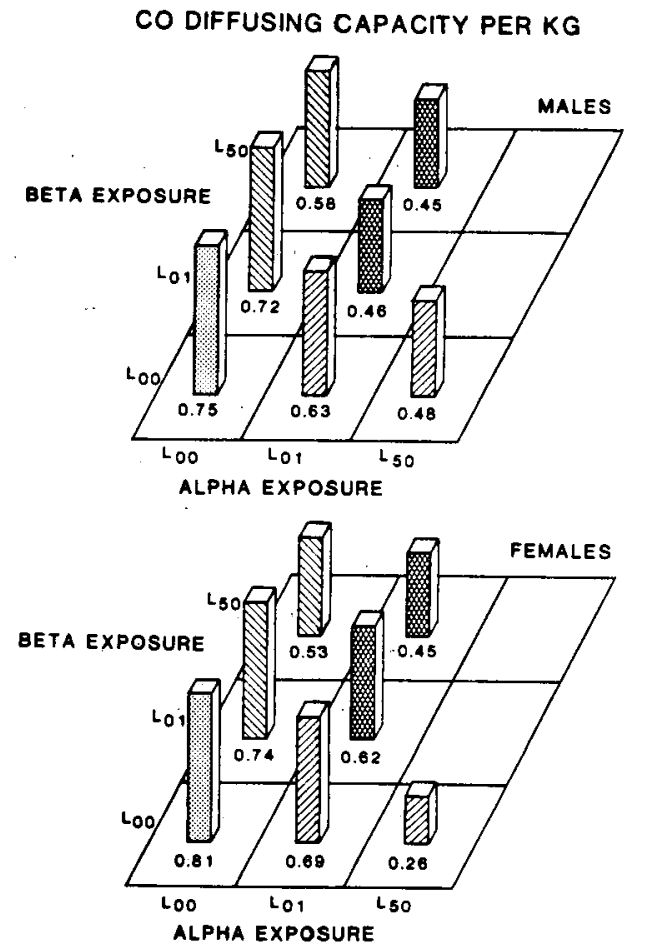

Figure 3.12. Average value for co diffusing capacity per $\mathrm{kg}$ body weight, as a function of the exposure level, at 1.5 years after inhalation exposure, and expressed in ;ml/min/mmHg/kg; (a) males, (b) females.

SLOPE PHASE 3
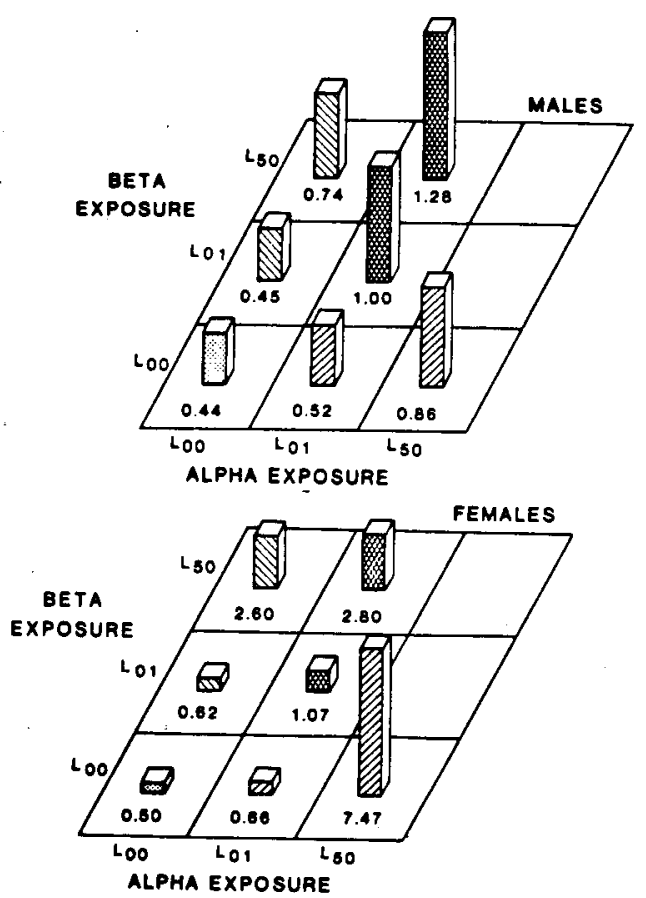

Figure 3.14. Average value for slope of phase III of the single breath nitrogen washout curve expressed in $\% \mathrm{~N}_{2} / \mathrm{ml}$, as a function of the exposure level, at 1.5 years after inhalation exposure; (a) males, (b) females. 
Rats having one or more of these abnormalities were assigned a risk parameter $R_{1}=1$; otherwise, $R_{1}=0$; rats having two or more abnormalities were assigned a risk parameter $R_{2}=1$; otherwise, $R_{2}=0$. Rats having three or more abnormalities were assigned a risk parameter $R_{3}=1$; otherwise $R_{3}=0$. Risk parameters $R_{1}, R_{2}$, and $R_{3}$ were examined theoretically to see which would best represent radiation-induced effects.

It is reasonable to assume, for a given gender, that values for the vital capacity, co diffusing capacity per $\mathrm{kg}$ body weight, quasistatic compliance, and slope of phase III of the single breath $\mathrm{N}_{2}$ washout curve each are normally distributed. If so, $R_{1}$ would be expected to lead to the wrong conclusion about radiation induced effects about $20 \%$ of the time when there are no radiation induced effects; similarly, the use of $R_{2}$ would be expected to lead to the wrong conclusion $1.5 \%$ of the time; however, the use of $R_{3}$ would be expected to lead to the wrong conclusion only $0.05 \%$ of the time. Thus, we selected $R_{3}$ as the risk parameter to use in defining the presence or absence of pulmonary functional morbidity after irradiation of the lung. A value of $R_{3}=1$ was taken to indicate pulmonary functional morbidity due to injury to the lung. A value of $R_{3}=0$ was taken to indicate the absence of pulmonary functional morbidity.

A modified version of the Weibull model was then used to fit the data for the prevalence of pulmonary functional morbidity at 1.5 years after inhalation exposure to $238 \mathrm{Pu}$ or $147 \mathrm{Pm}$. Data for combined exposure to both radionuclides were not fitted but were reserved for model validation. The modified model is given by

$$
\text { Prevalence }=R_{0}+\left(1-R_{0}\right) R
$$

where $R$ is the same type of Weibull function as in Equation 7, and $R_{0}$ accounts for effects not due to irradiation. Use of this form of the Weibull model allows the determination of a shape parameter $V$ and ILB50 for morbidity even though some rats may have pulmonary morbidity unrelated to irradiation. Using a maximum likelihood approach so that individual datum points could be used, the ILB50 was estimated for the prevelance of pulmonary morbidity among rats exposed to $238 \mathrm{Pu}$ only or $147 \mathrm{Pm}$ only. Because of the small sample sizes used, the shape parameter could not be adequately determined and was therefore assumed to be the same as for lethality from RPPF. For $238 \mathrm{pu}$, the ILB50 for pulmonary morbidity was $30 \pm 3 \mathrm{nCi} / \mathrm{g}-1$ ung. For $147 \mathrm{Pm}$, it was $40 \pm 4$ $\mu \mathrm{Ci} / \mathrm{g}-\mathrm{lung}$. Corresponding $\mathrm{O}_{50}$ values for $238 \mathrm{Pu}$ alphas and $147 \mathrm{Pm}$ betas, based on cumulative radiation doses to the lung at 1.5 years after inhalation exposure, were $1,100 \pm 110$ rad (11 Gy) and $7,500 \pm 750 \mathrm{rad}(75 \mathrm{~Gy})$, respectively. The parameter $R_{0}$ was found to be zero for these data. However, we have retained the modified model so that results can be compared with those obtained at Pacific Northwest Laboratory (PNL) by Dr. R. Filipy and coworkers who are using the same model.

Because the shape parameters for morbidity could not be adequately determined, a value of 5 was assumed and used. With the ILB 50 's and shape parameter given, doses in units of the ILB50 couid be calculated for those rats exposed to both alpha and beta radiation; this was achieved by dividing the initial lung burden of $238 \mathrm{pu}$ in $\mathrm{nci} / \mathrm{g}-1$ ung by 30 and dividing the initial lung burden of $147 \mathrm{Pm}$ by 40 and adding the results to obtain the total dose $x$ in units of the ILB50 or $D_{50}$. The individual risk for the prevalence of morbidity at 1.5 years was then calculated using

$$
\text { Individual risk }=1-\exp \left[-\mathrm{H}_{m}\right] \text {. }
$$

where the morbidity hazard $H_{m}$ is given by

$$
H_{m}=\ln (2) \star x^{5}
$$

for radiation-induced pulmonary functional morbidity. 
Adding the individual risk for a given ILB distribution over a given exposure level and dividing by the number of rats in the level gave the average risk for that level and for that ILB distribution. This average risk can only be used for the specific ILB distribution used to derive it because of the nonlinear shape of the curves for morbidity. The expected number of morbidity cases at a given exposure level is equal to the product of the average risk times the number of rats in the exposure level. Using the same hazard-function approach as was used for mortality from RPPF, the number of morbid rats at 1.5 years after combined alpha and beta irradiation of the lung was predicted for experimental groups $A B 2$ and $A B 4$. Predicted and observed values are given in Table 3.6 and are in good agreement.

Table 3.6

Predicted and Observed Cases of Respiratory Functional Morbidity Among F344/Crl Rats After Combined Alpha and Beta Irradiation of the Lung from Inhaled $147 \mathrm{Pm}$ and $238 \mathrm{Pu}$ in

Fused Aluminosilicate Particles*

\begin{tabular}{|c|c|c|c|c|c|c|}
\hline \multirow{2}{*}{$\begin{array}{l}\text { Experiment } \\
\text { Group } \\
\end{array}$} & \multirow{2}{*}{$\begin{array}{l}\text { Number } \\
\text { Surviving } \\
\text { Rats } \\
\end{array}$} & \multicolumn{2}{|c|}{ Dose $(\operatorname{Rads})^{\star \star}$} & \multirow{2}{*}{$\begin{array}{c}\text { Predicted } \\
\text { Average } \\
\text { Risk } \\
\end{array}$} & \multirow{2}{*}{$\begin{array}{l}\text { Predicted } \\
\text { Cases of } \\
\text { Morbid Rats } \\
\end{array}$} & \multirow{2}{*}{$\begin{array}{l}\text { Observed } \\
\text { Cases of } \\
\text { Morbid Rats }\end{array}$} \\
\hline & & Alpha & Beta & & & \\
\hline$A B 2$ & 19 & 840 & 10400 & 0.97 & $18.5 \pm 0.7$ & 18 \\
\hline$A B 4$ & 5 & 840 & 2640 & 0.54 & $2.7 \pm 1.1$ & 4 \\
\hline$c$ & 20 & 0 & 0 & 0 & 0 & 0 \\
\hline Al & 6 & 4350 & 0 & 1 & 6 & 6 \\
\hline A2 & 19 & 930 & 0 & 0.29 & $5.5 \pm 2.0$ & 5 \\
\hline B1 & 13 & 0 & 8780 & 0.65 & $8.5 \pm 1.7$ & 10 \\
\hline B2 & 16 & 0 & 2910 & 0.04 & $0.7 \pm 0.8$ & 1 \\
\hline
\end{tabular}

\footnotetext{
*Predictions were only made for Groups $A B 2$ and $A B 4$ where rats were exposed to both alpha and beta radiations. There were no survivors in Group $A B I$ and only one survivor in Group $A B 3$ at 1.5 years. Values listed for Groups $C, A 1, A 2, B 1$ and $B 2$ are not predictions; data from these groups were fitted. with the Weibull doseresponse model to obtain model parameters to use to predict the results for Groups $A B 2$ and $A B 4$.
}

**Group average cumulative 1.5 year radiation dose to lung.

In earlier mortality experiments, in which rats were exposed via inhalation to one or more beta-emitting radionuclides (NUREG/CR-5025, 1987), the shape parameter for lethality from RPPF was also found to be about 5 , and seemed to be independent of beta dose rate. It is shown in Table 3.7 that the ILB50 for acute lethality is about 4 times larger than that for morbidity. Corresponding doses to 1.5 years after inhalation exposure are given in Table 3.8. These results suggest that the same model used for acute mortality from beta irradiation to the lung could be used for morbidity if the $0_{50}$ parameters for mortality are reduced by a factor of 4 for low energy betas.

A similar analysis of data from previous experiments in which $\mathrm{F} 344 / \mathrm{Cr}$ rats inhaled mainiy $90 y$ or an equilibrium mixture of $90 \mathrm{Sr}+90 \mathrm{Y}$ in fused aluminosilicate particles (NUREG/CR-5025, 1987) did not reveal any significant difference between the median-lethal and median-effective doses for morbidity. Both $90 \mathrm{Y}$ and $90 \mathrm{Sr}$ are high-energy beta emitters with average energies of 0.935 and $0.196 \mathrm{MeV}$, respectively; while for $147 \mathrm{Pm}$, the average energy is only $0.062 \mathrm{MeV}$. The 
Table 3.7

Median Lethal Lung Burdens for Death* from Radiation Penumonitis and Pulmonary Fibrosis and Median Effective Lung Burdens for Respiratory Morbidity After Inhalation Exposure

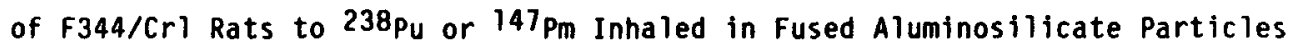

Type of Radiation 238pu alphas $\frac{\text { Median Lethal }}{123 \pm 7.5 \mathrm{nCi} / \mathrm{g}-\text { lung }}$ Median Effective $30 \pm 3 \mathrm{nCi} / \mathrm{g}-1 \mathrm{ung}$ Ratio*k $147 \mathrm{Pm}$ betas $160 \pm 190 \mu \mathrm{C} i / \mathrm{g}-\mathrm{lung}$ $40 \pm 4$ uCi/g-lung 4.1 Average Ratio $=4.0$

*Death within 1.5 years.

**Median lethal divided by median effective burden.

Table 3.8

Median Lethal 1.5 Year Radiation Doses to the Lung for Death Within 1.5 Years From Radiation Pneumonitis and Pulmonary Fibrosis and Median Effective Doses for Respiratory Morbidity at 1.5 Years After Inhalation Exposure of F344/Crl Rats to $238 \mathrm{pu}$ or $147 \mathrm{Pm}$ Inhaled in Fused Aluminosilicate Particles

\begin{tabular}{|c|c|c|c|}
\hline $\begin{array}{c}\text { Type of } \\
\text { Radiation } \\
\end{array}$ & $\begin{array}{l}\text { Median } \\
\text { Lethal } \\
(\text { rads })^{\star}\end{array}$ & $\begin{array}{l}\text { Median } \\
\text { Effective } \\
\text { (rads)* }\end{array}$ & Ratio* \\
\hline${ }^{238} \mathrm{Pu}$ alphas & 4,500 & 1,100 & 4.1 \\
\hline $147 \mathrm{Pm}$ betas & 30,000 & 7,500 & 4.0 \\
\hline 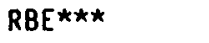 & 6.7 & 6.8 & \\
\hline
\end{tabular}

*1.5 year dose. Multiply beta dose by 0.88 to get 1 -year dose. Multiply alpha dose by 0.85 to get 1 -year dose.

**Median lethal divided by median effective dose.

***For 1.5 year followup.

results therefore suggest that the factor of 4 derived for comparing lethality and morbidity (respiratory dysfunction) may be applicable to alpha and low-energy beta radiations only.

Data in Table 3.8 were used to estimate the relative biological effectiveness of $238 \mathrm{pu}$ alphas relative to $147 \mathrm{Pm}$ betas. An RBE of approximately 7 was obtained for both lethality and morbidity.

Dose-effect surfaces are given in Figures 3.15 and 3.16 for 1.5 -year lethality from RPPF and for the prevalence of pulmonary morbidity at 1.5 years after inhalation exposure to a mixture of $238 \mathrm{Pu}+147 \mathrm{Pm}$ inhaled in an insoluble form. Although the results are based on studies with $\mathrm{F} 344 / \mathrm{Cr} 1$ rats, it is assumed that they are also applicable to man. 


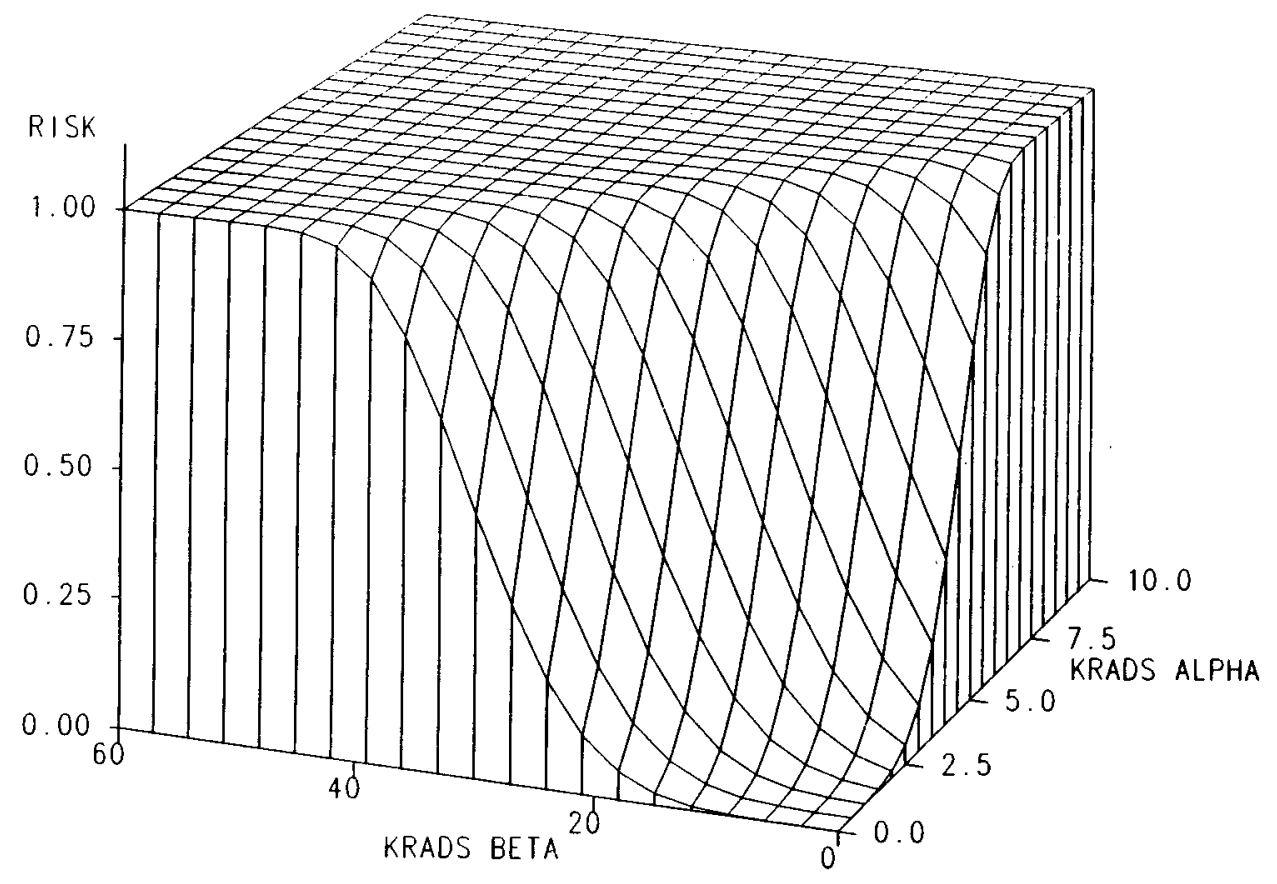

Figure 3.15 Dose-effect surface for $F 344 / C r l$ rats for estimating the 1.5 -year lethality risk for death from radjation pneumonitis and pulmonary fibrosis after inhalation exposure to mixtures of $238 \mathrm{Pu}+147 \mathrm{Pm}$ inhaled in an insoluble form. Results are based on the hazard-function mode1. Doses represent 1.5 -year doses to the lung.

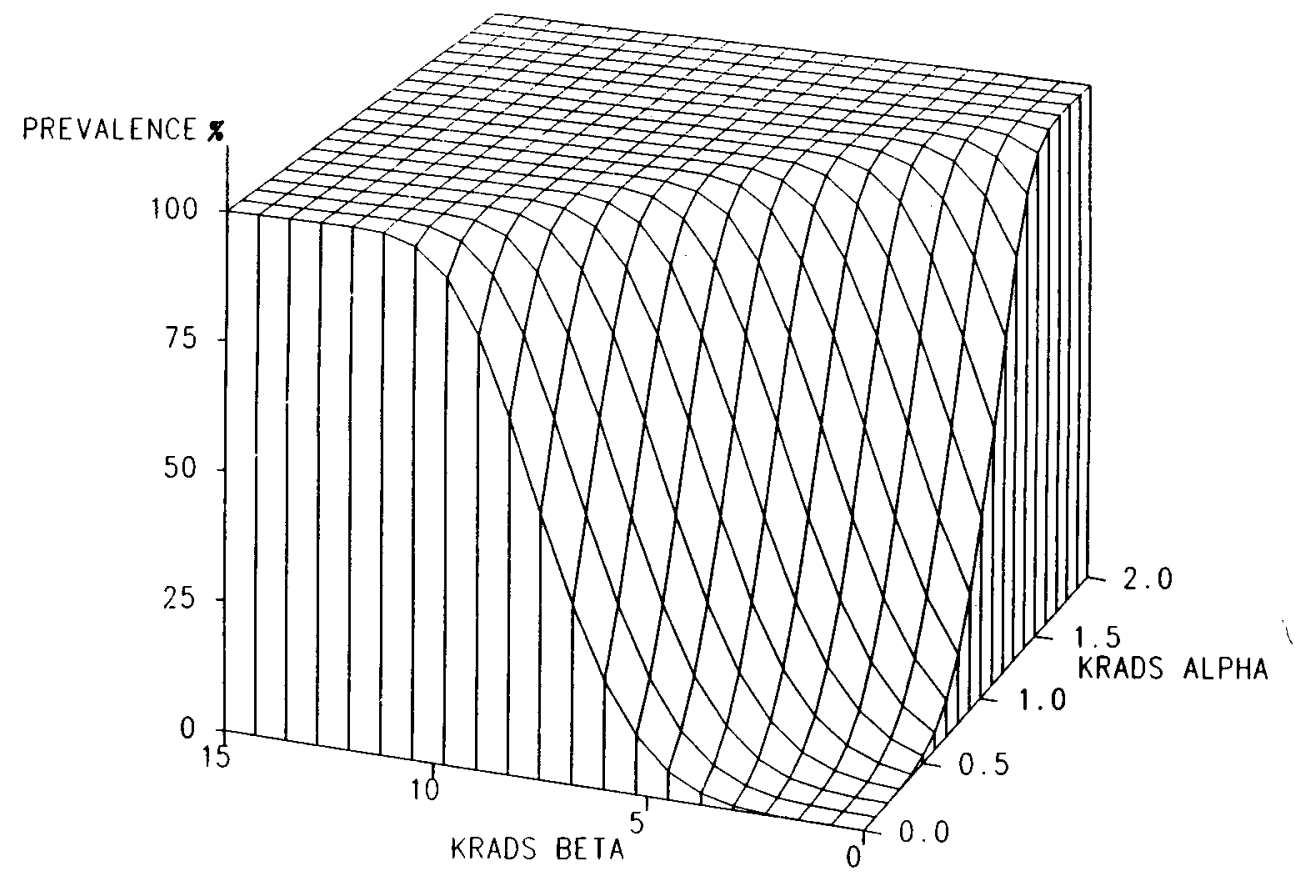

Figure 3.16 Dose-effect surface for $\mathrm{F} 344 / \mathrm{Cr}$ rats for estimating the prevalence of respiratory morbidity at 1.5 years after inhalation exposure to mixtures of $238 \mathrm{Pu}+147 \mathrm{Pm}$ inhaled in an insoluble form. Doses represent 1.5 -year doses to the lung. 
The experiment described in this document was part of a series of inhalation exposure experiments carried out at the Inhalation Toxicology Research Institute to validate a mortality model (Scott et al., 1986) developed for predicting deaths from RPPF after inhalation exposure to mixtures of alpha- and beta-emitting radionuclides. Results of the experiment demonstrated that the hazard-function model adequately predicted the observed deaths from RPPF that occurred throughout the 1.5-year observation period.

Hematological evaluations were carried out on rats assigned to the hematology group at various times after inhalation exposure. However, no significant effects on the peripheral blood could be demonstrated. The implications are that low energy betas from $147 \mathrm{Pm}$ and alphas from $238 \mathrm{pu}$ deposited in the lung do not deliver significant doses to the radiosensitive bone marrow because of their short range in tissue. In addition, combined alpha and beta irradiation of the blood traversing the lung does not lead to any significant alterations in the cellularity of the peripheral blood of rats.

Body weights of all rats were recorded at various times after inhalation exposure. Significant alterations in body weights were observed mainly in rats with lethal doses to the lung. The results indicate that body weight change is not a good indicator of morbidity among survivors.

Pulmonary function was evaluated in survivors at 1.5 years after inhalation exposure. It was demonstrated using pulmonary function measurements for the vital capacity, co diffusing capacity, quasistatic compliance, and slope of phase 3 of the $\mathrm{N}_{2}$ washout curve that irradiation of the lung leads to a reduction in lung volume, a decreased efficiency in gas exchange, a stiffer lung and an altered intrapulmonary gas distribution in some rats. These changes are all characteristic of RPPF and occurred at doses approximately one fourth of that required for acute lethality. A hazard-function model was developed for predicting the prevalence of pulmonary functional morbidity among rats exposed to both alpha and beta radiation. Model predictions were demonstrated to be in good agreement with experimental observations.

Assuming that these results are applicable to man, the implication is that a $239 \mathrm{pu}-\mathrm{alpha}$ dose to the lung of approximately $1.100 \mathrm{rad}(11 \mathrm{~Gy})$ or a $147 \mathrm{Pm}$-beta dose of approximately 7,500 rad (75 Gy) could cause pulmonary functional morbidity in one-half of those exposed. In a recent report by Muggenburg et al. (1986), it was demonstrated that 239 pu-alpha. doses from 240 to 730 rad $(2.4$ to $7.3 \mathrm{~Gy})$ to the lung of dogs caused clinical signs and pulmonary function values indicating RPPF at 7.1 years after inhalation exposure.

Among 19 rats exposed to $238 \mathrm{pu}$-alpha doses (1.5 year doses) from 670 to 1.500 rad (6.7 to 15 Gy) to the lung, five had pulmonary functional morbidity, based on the risk parameter $R_{3}$. All of these five also had septal fibrosis, suggesting that the fibrosis may have been a cause of the functional morbidity.

Among 29 rats that had 1.5 year $147 \mathrm{Pm}$-beta doses to the lung from 1,100 to 13,000 rad $(11$ to $130 \mathrm{~Gy})$, 11 had pulmonary functional morbidity, based on the risk parameter $R_{3}$. All except one of these 11 rats had septal fibrosis, suggesting that the fibrosis may have been a cause of the functional morbidity.

Together, the results presented imply that doses required for causing acute lethality from RPPF after alpha or low-energy-beta irradiation of the lung are considerably higher than those required for causing pulmonary functional morbidity. The results also indicate that pulmonary functional morbidity can be prevalent after more than a year of prolonged alpha or low-energy-beta irradiation of the lung. 
After adjusting for competing modes of death, 80 rats were judged at risk for death from RPPF. Of these, 43 deaths were expected and 54 were observed. Also, for rats receiving combined alpha and beta irradiation of the lung, 21 out of 24 surviving rats were expected to have pulmonary functional morbidity while 22 cases were observed. The results indicate that the hazard-function mortality and hazard-function morbidity models for combined alpha and beta irradiation of the lung should be adequate for reactor accident risk assessment.

\section{REFERENCES}

1. Harkema, J. R., Mauderly, J. L., and Hahn, F. F. (1982): The Effects of Emphysema on 0xygen Toxicity in Rats. Am. Rev. Respir. Dis. 126:1058-1065.

2. Keough, R. F. and Powers, G. J. (1970): Determination of Plutonium in Biological Materials by Extraction and Liquid Scintillation Counting. Anal. Chem. $42: 419$.

3. Mauderly, J. L., Muggenburg, B. A., Hahn, F. F., and Boecker, B. B. (1980A): The Effects of Inhaled ${ }^{144} \mathrm{Ce}$ on Cardiopulmonary Function and Histopathology of the Dog. Radiat. Res. 84: $307-324$.

4. Mauderly, J. L., Mewhinney, J. A., and Boecker, B. B. (1980B): A Comparison of the Effects of Inhaled Alpha- and Beta-Emitting Radionuclides on Pulmonary Function in the Dog. In Pulmonary Toxicology of Respirable Particles (C. L. Sanders, F. T. Cross, G. E. Dagle, and J. A. Mahaffey, eds.), Technical Information Centers, U. S. Department of Energy, pp. 404-419.

5. Muggenburg, B. A., Wolff, R. K., Mauderly, J. A., Plaggmier, M. M., and Gerlach, R. F. (1986): Cardiopulmonary Function of Dogs With Plutonium-Induced Chronic Lung Injury. In Inhalation Toxicology Research Institute Annual Report 1985-1986, LMF-115, pp. 251-256.

6. Scott, B. R., Hahn, F. F., Newton, G. J., Snipes, M. B., Damon, E. G., Mauderly, J. L., Boecker, B. B., and Gray, D. H. (1987): Experimental Studies on the Early Effects of Inhaled Beta-Emitting Radionuclides for Nucelar Accident Risk Assessment. NUREG/CR-5025.

7. SAS (1982): SAS User's Guide: Statistics. SAS Institute, Cary, NC.

8. Scott, 8. R. (1987): A Radiation Protection Approach to Assessing Population Risks for Threshold Type Radiobiological Effects. In Proceedings of the 25 th Hanford Life Science Symposium Radiation Protection - A Look to the Future (in press).

9. Scott, B. R., Hahn, F. F., Guilmette, R. A., Muggenburg, B. A., Snipes, M. B., Boecker, B. B., and McClellan, R. 0. (1986): Use of Studies With Laboratory Animals to Assess the Potential Early Health Effects of Combined Internal Alpha and Beta Irradiation. In Life-Span Radiation Effects Studies in Animals: What Can They Tel1 Us? (Roy C. Thompson and. J. A. Mahaffey, eds.), CONF-830951, pp. 578-591.

10. Scott, B. R. and Hahn, F. F. (1985): Early Occurring and Continuing Effects. In Health Effects Model for Nuclear Power Plant Accident Consequence Analysis. Volume II, Chapter 1 , NUREG/CR-4214, SAND85-7185.

11. Scott, B. R., Hahn, F. F., Cuddihy, R. G., Boecker, B. B., and Seiler, F. A. (1984): Hazard-Function Modeling of Early Effects Mortality Risks Associated With Light Water Nuclear Reaction Accidents. In Proceedings of the 1984 Statistical Symposium on National Energy Issues, PNL-SA-13085, NUREG/CP-0063, Pp. 134-152.

12. Snipes, M. B. (1980): Fraction of Energy Absorbed from B-Emitting Particles in the Rat Lung. Radiat. Res. 81:161-169. 
APPENDIX: DATA BASES

Listing of rats exposed to aerosols of alpha- or beta-emitting radionuclides or both in fused aluminosilicate particles (FAP).

1. Rats exposed to aerosols of $238 \mathrm{Pu}$ FAP, $147 \mathrm{Pm}$ FAP, or $238 \mathrm{Pu}+147 \mathrm{Pm}$ in FAP.

2. Pulmonary function measurements in rats exposed to aerosols of $238 \mathrm{Pu}$ FAP, 147Pm FAP, or $238 p_{u}+147 p_{m}$ in FAP. 
1A. PATHOLOGICAL OBSERVATIONS AND OTHER COMMENTSFOR RATS THAT DIED, WERE SACRIFICED OR EUTHANIZED AFTER INHALATION EXPOSURE TO 238 PU, 147 Pm OR BOTH IN FAP

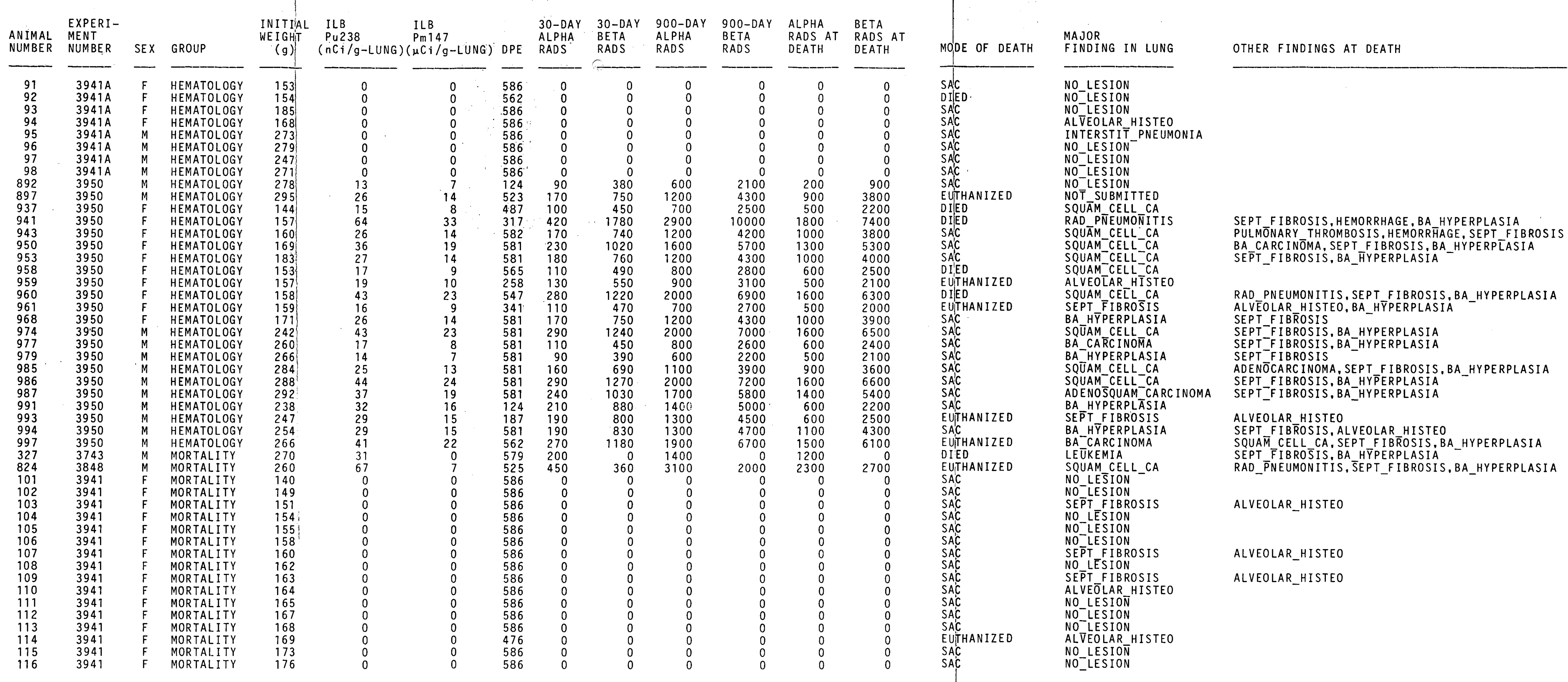




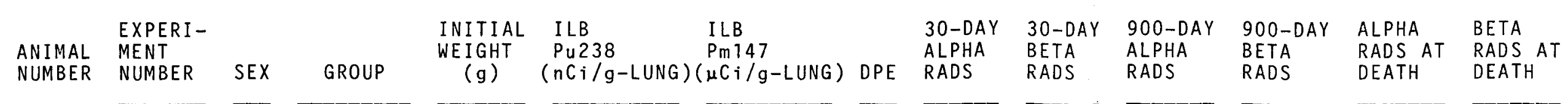

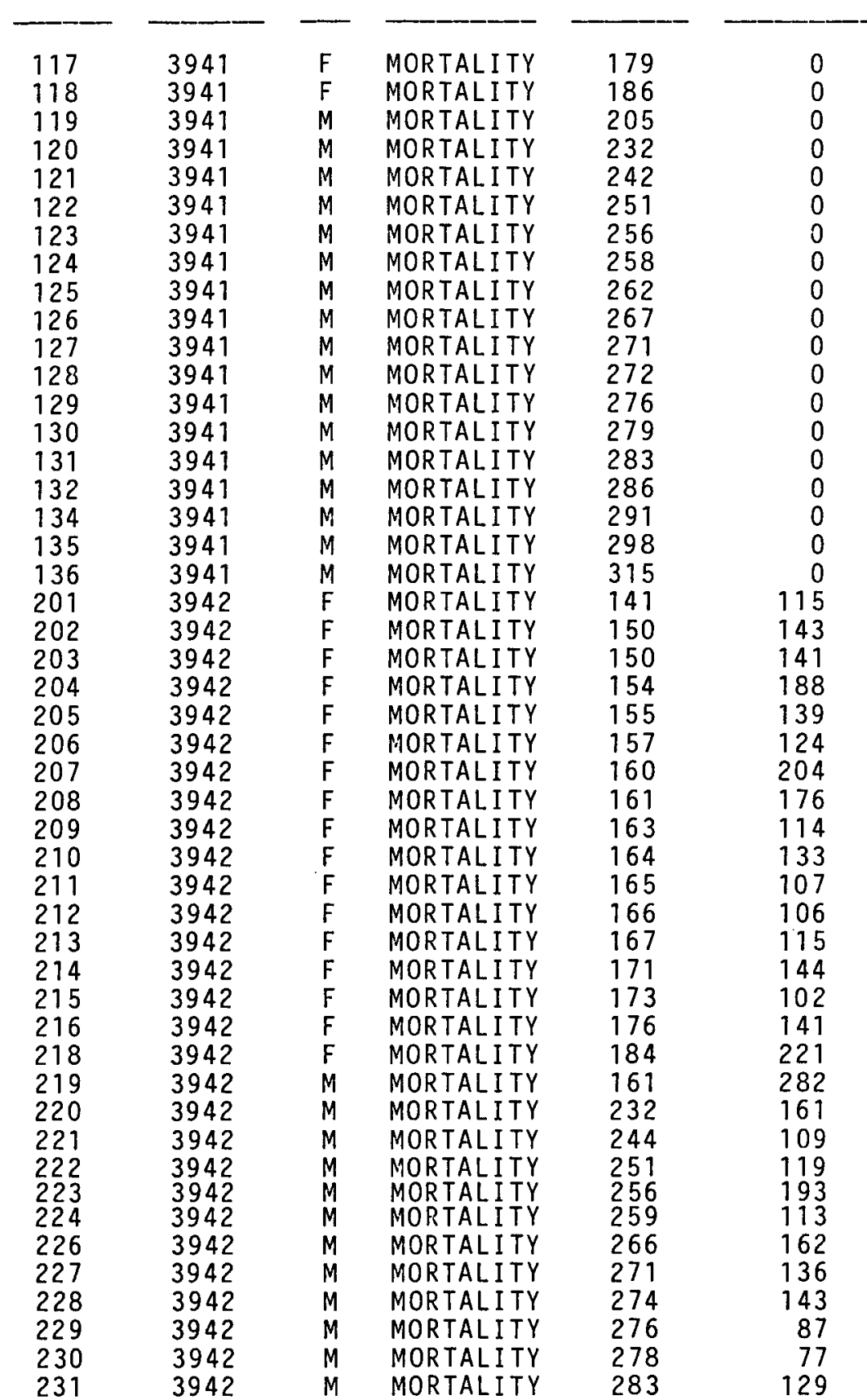

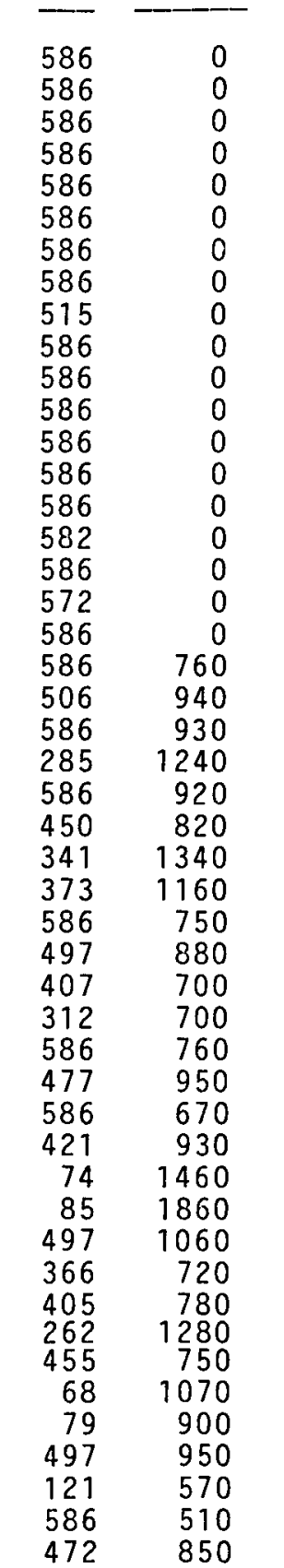

MasoR

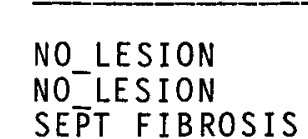

SEPT FIBROSIS
NO - LESTON
NO LESION

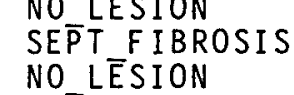

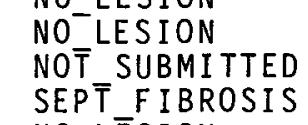

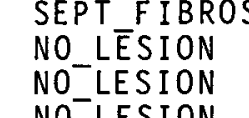

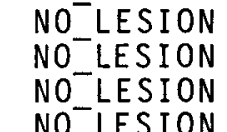

NO-LESTON
NOLESIONS
NO LESTONS
SETT FIBROSIS

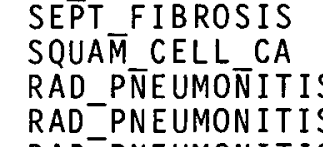

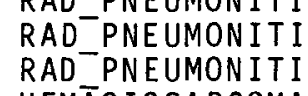

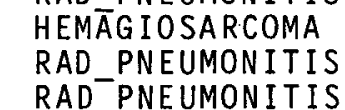

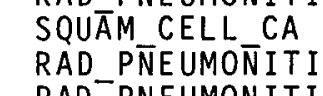

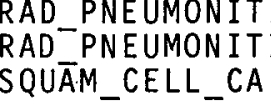

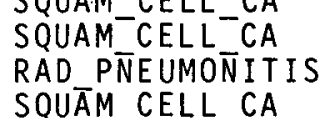

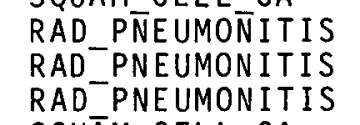

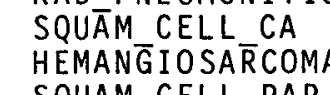

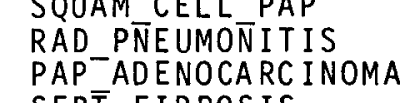

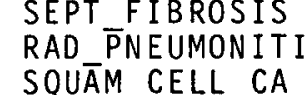

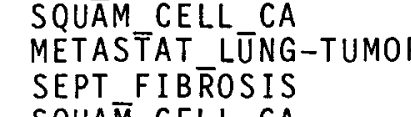

OTHER FINDIIGGS AT DEATH

ALVEOLAR_HISTEO

ALVEOLAR_HISTEO

aLVEOLAR_HISTEO

ALVELLAR HISTEO

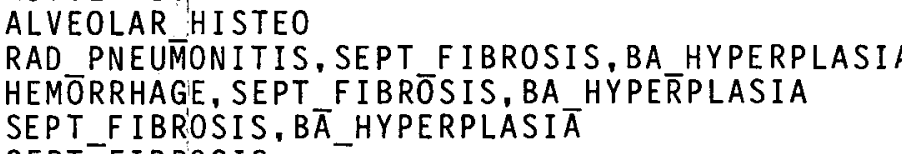

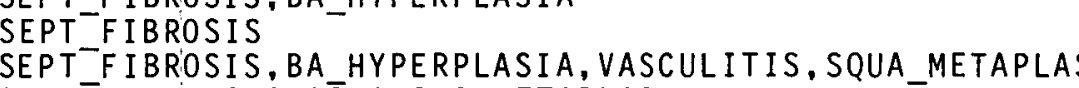

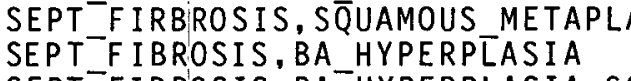

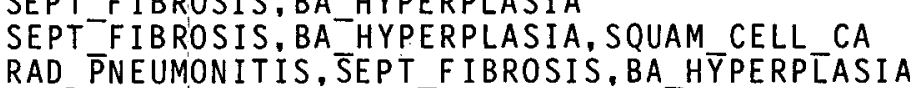

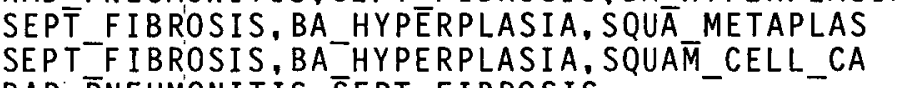

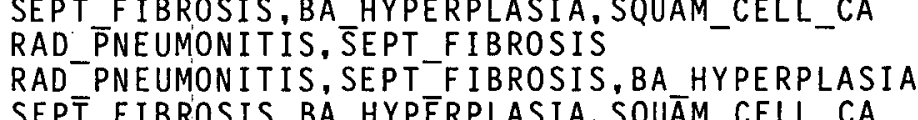

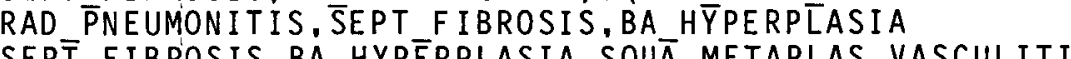

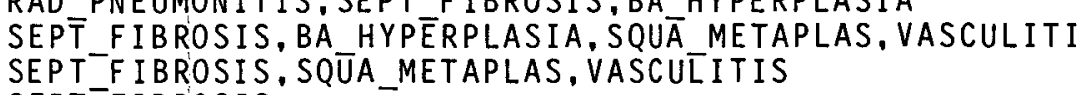

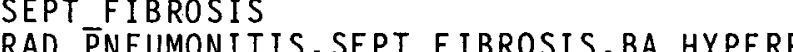

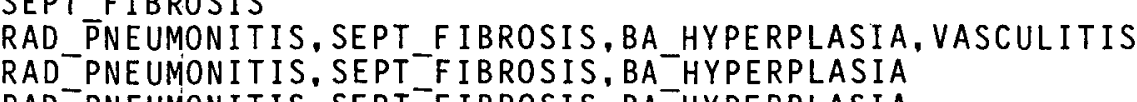

MPRPALIA

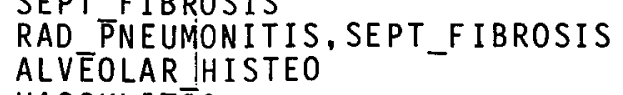

VASCULITIS ISTS BA HYPERPLASIA

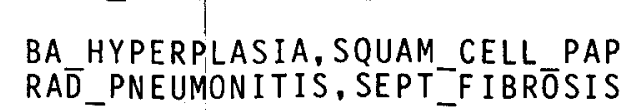




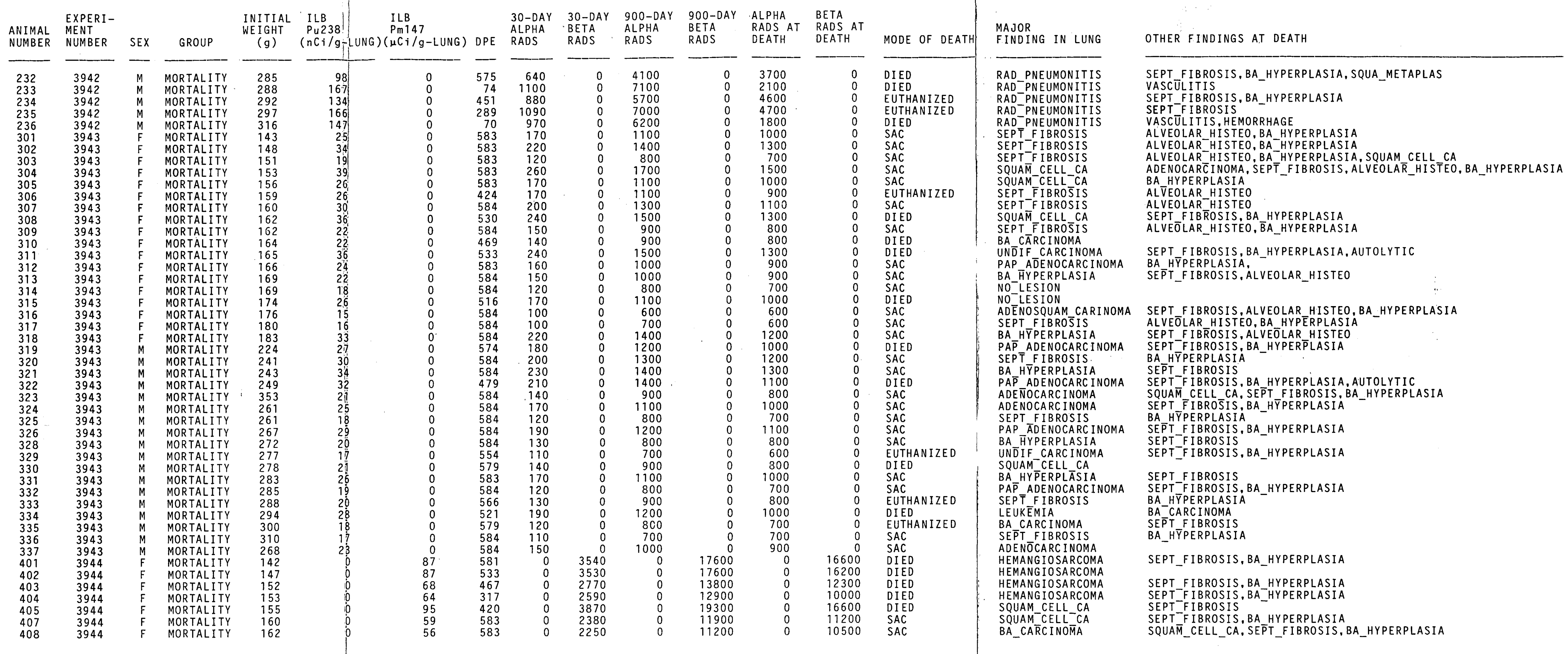




\section{3}

1D. PATHOLOGICAL OBSERVATIONS AND OTHER COMMENTS FOR RATS that DIED, WERE SACRIFICED OR EUTHANIZED AFTER INHALATION EXPOSURE TO 238 Pu, 147 Pm OR BOTH IN FAP

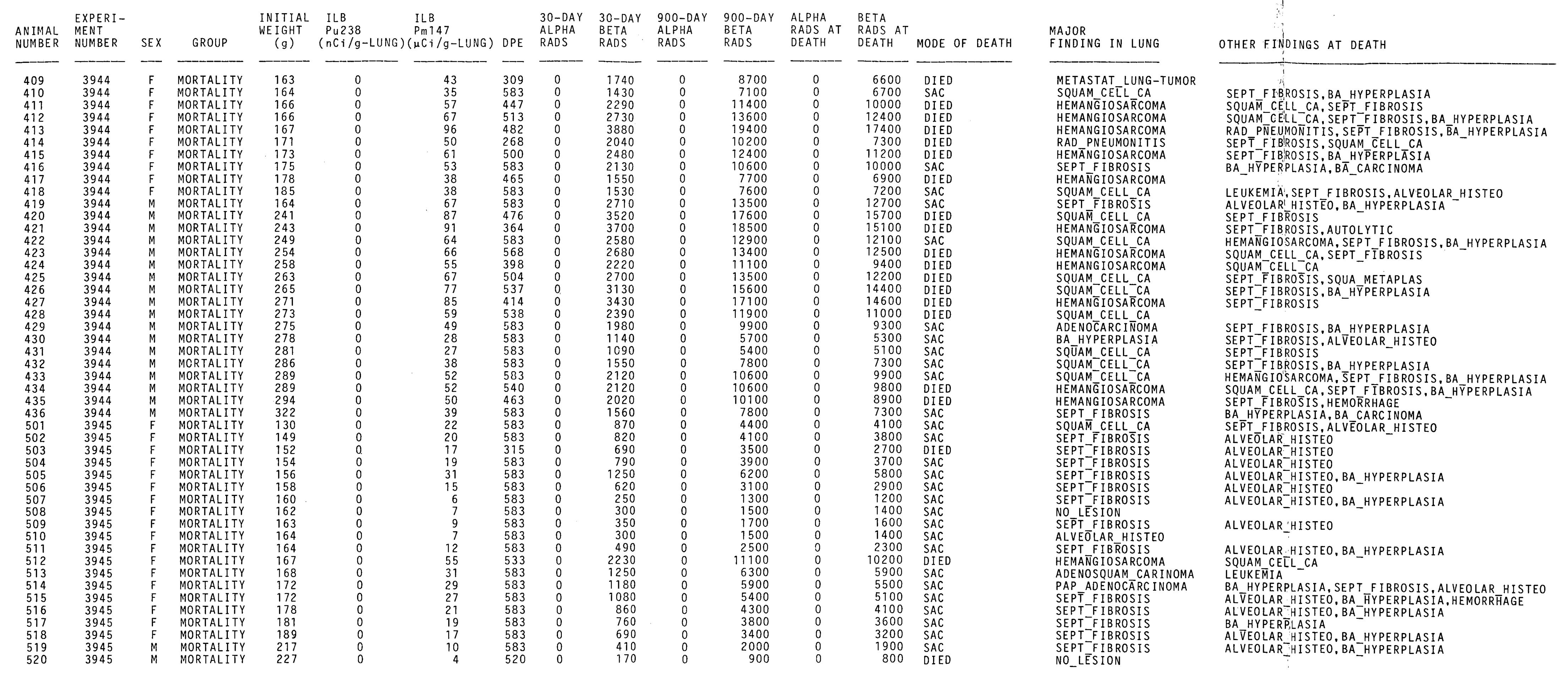




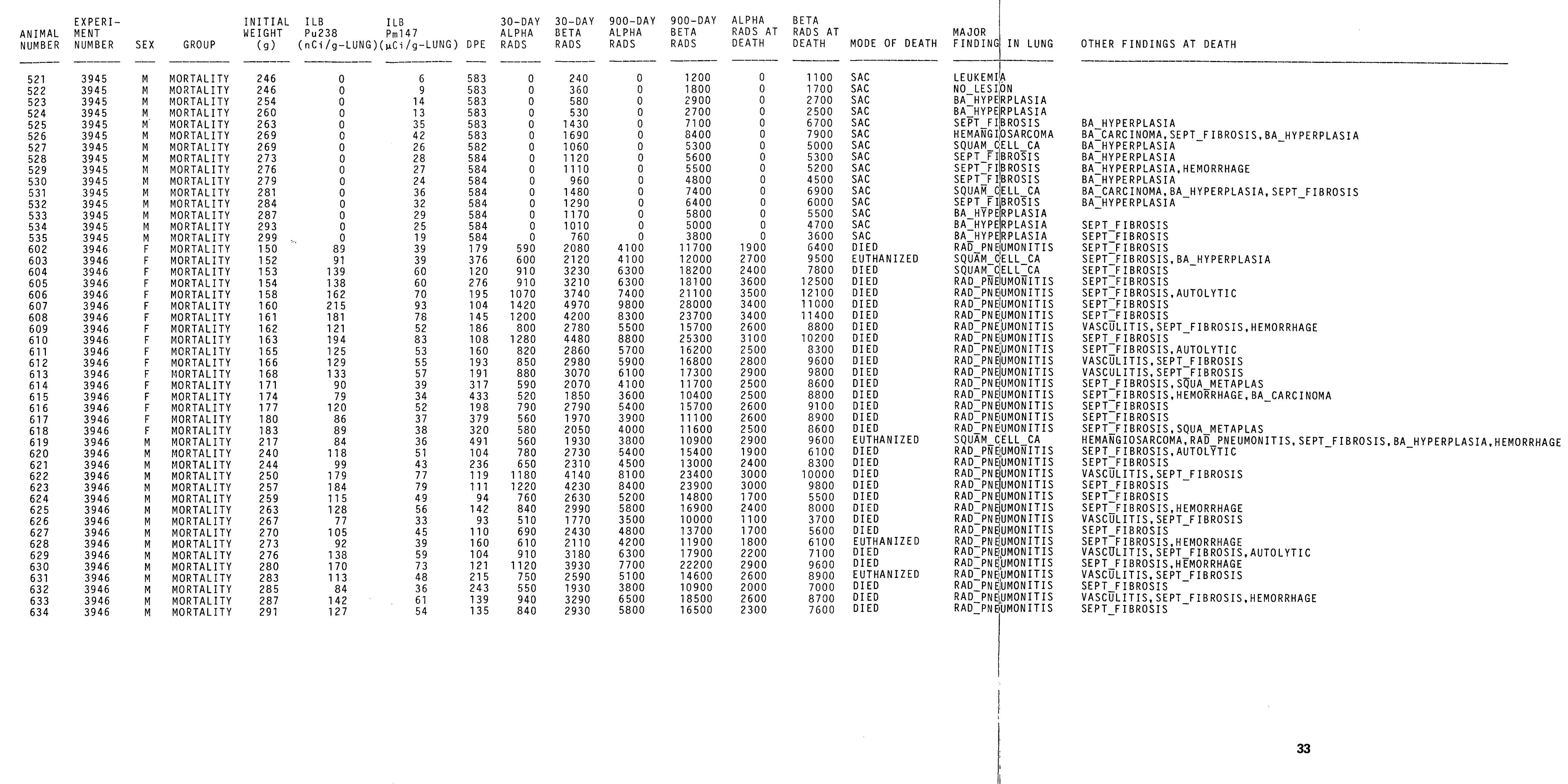




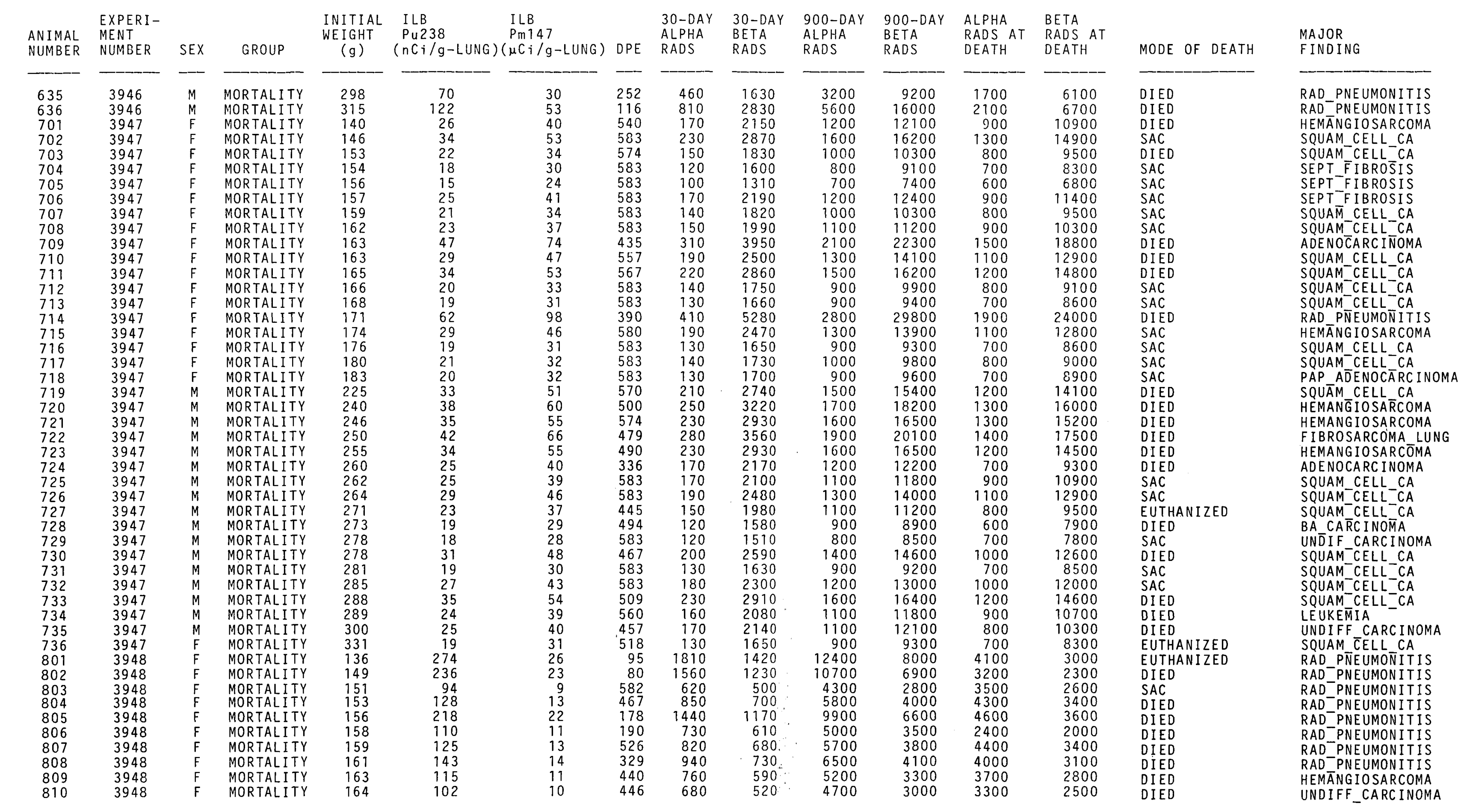

OTHER FINDINGS AT DEATH

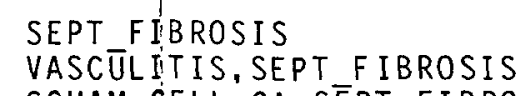

SOUAM CEELCA, SEPT FIBRSIS, BA HYPERPLASIA
SEPT FIBROSIS,BBA HYPERPLASIA,INTERSTIT PNEUMONIA

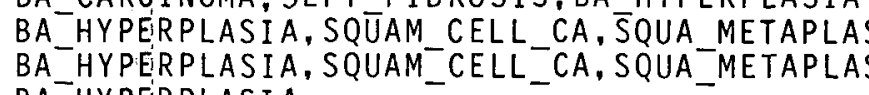

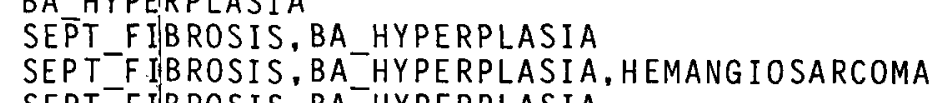

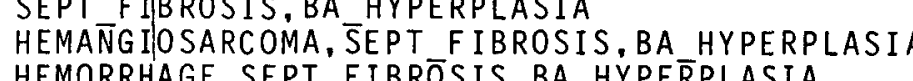

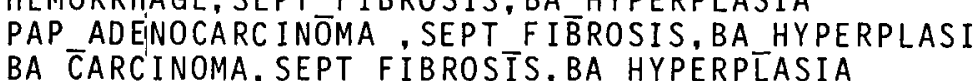

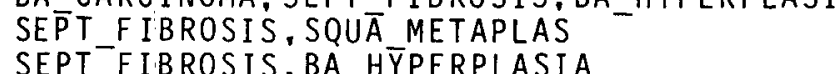

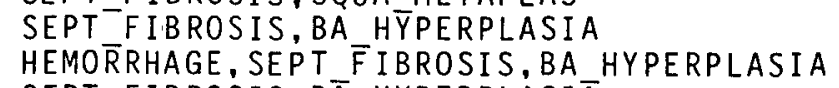

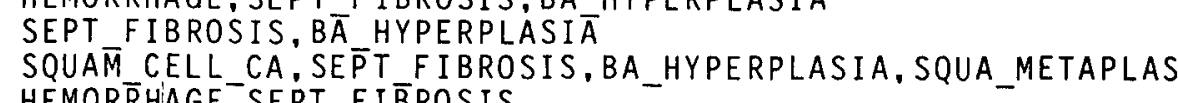

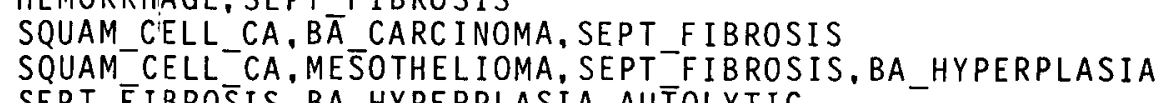

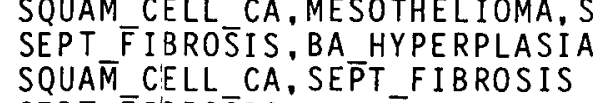

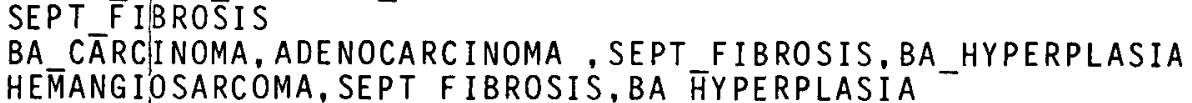

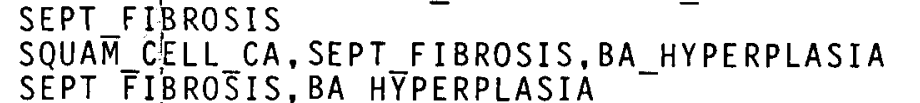
SEFT FIBROSIIS, BA HYPERPLASIA
HEMANGGIOSARCOMA, SEPT FIBROSIS, BA_HYPERPLASIA SEPT FIBROSI
SEPT FIRROSI

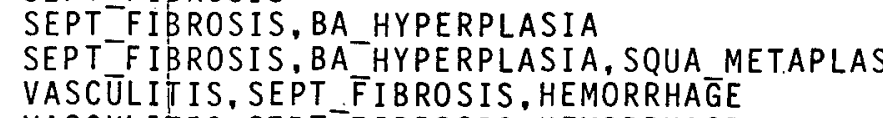

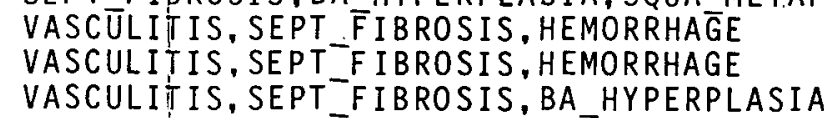
VASCÜLITIS SEPT FIBROSIS SEPT-FIRROSIS. AUTOLYTIC
SEPT FIBROSIS, SOUAM CEL CA

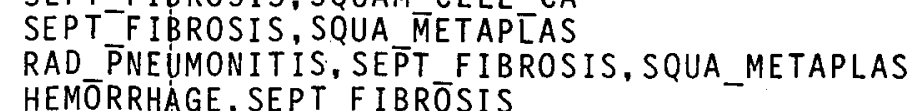


1G. PATHOLOGICAL OBSERVATIONS AND OTHER COMMENTS FOR RATS THAT DIED, WERE SACRIFICED OR EUTHANIZED AFTER INHALATION EXPOSURE TO 238 PU, 147 Pm OR BOTH IN FAP

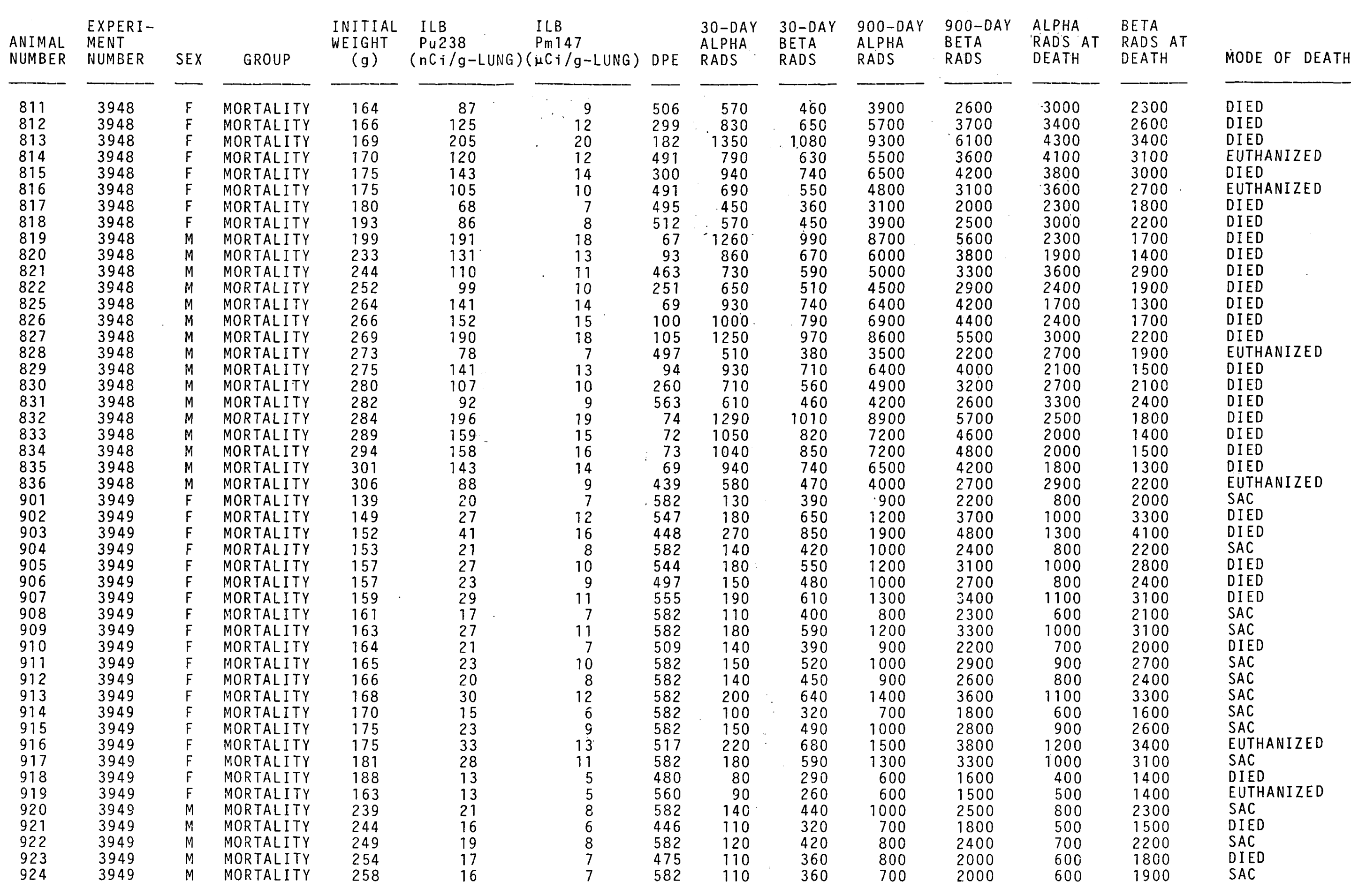

masop an the Lum

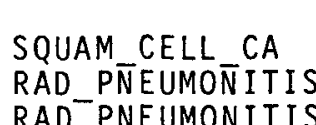

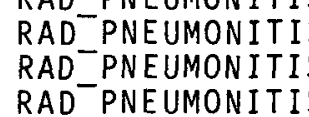

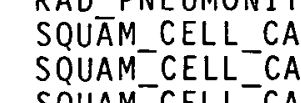

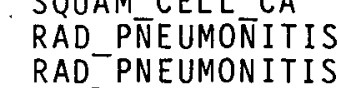

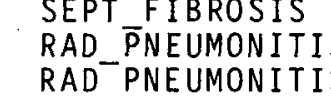

RAD-PMEUMONIII
RAD PEEUMONIII
RAT

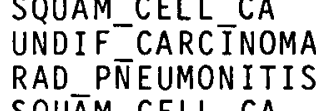

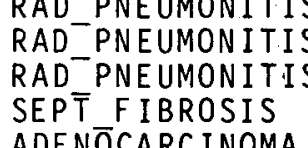

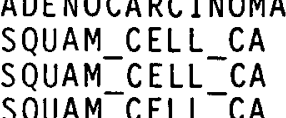

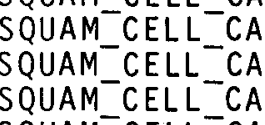

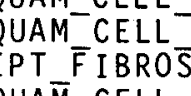

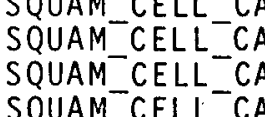

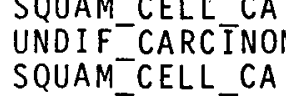

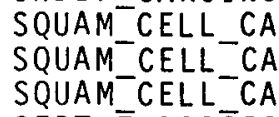

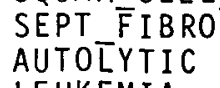

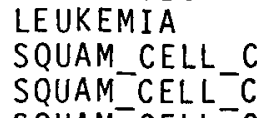

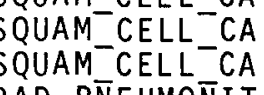

OTHER FINDINGS AT DEATH

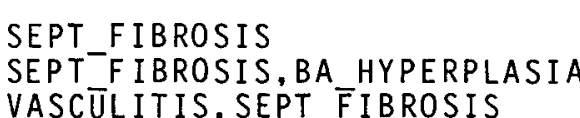

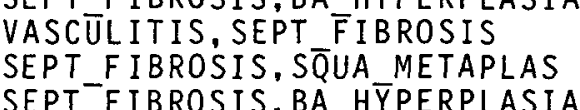

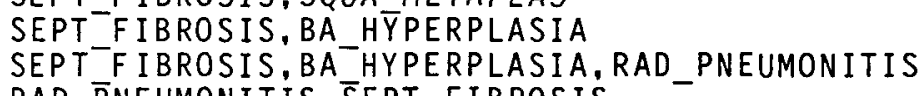

SEPT FIRROSIS
VASCULLIIIS.SEPT_FIBROSIS

SEPT FIBROSIS, SQUAM CELL_PAP

VASCULITIS. SEPT F F IBROSIS, HEMORRAAGE, AUTOLYTIC

SEPT FIBDOSIS AUTOLYTIC

SEPT FIBROSIS AUTOLYT

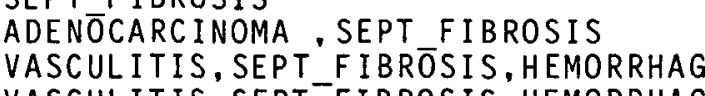

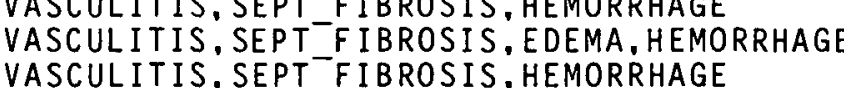

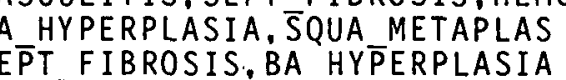

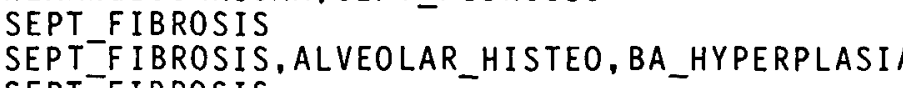

SEPTFFIRROSIS, BA_HYPERPLASIA, AUTOLYTIC

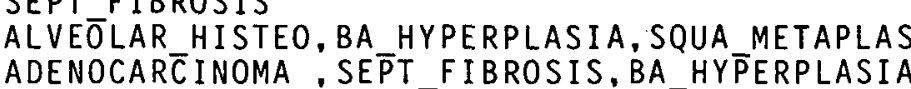

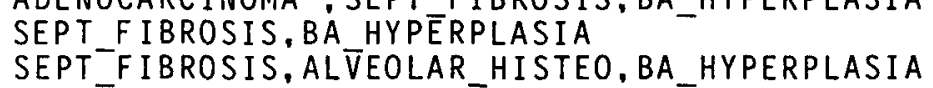

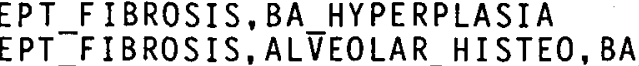

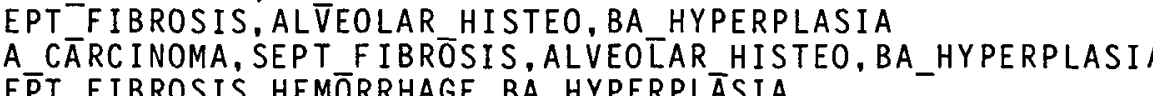
SEPT F F IBROSIS. SQUA-METAPLAS
ALVEOLLAR HISTEO, BA HYPERPLASIA

SEPT_F IBROSIS, ALVEOLAR_HISTEO

SEPT F FIBROSIS
BA HYPRPLASIA

BA CARCINOMA, SEPT TI FROSIS 
1H. PATHOLOGICAL OBSERVATIONS AND OTHER COMMENTS FOR RATS THAT DIED, WERE SACRIFICED OR EUTHANIZED AFTER INHALATION EXPOSURE TO 238 PU, 147 Pm OR BOTH IN FAP

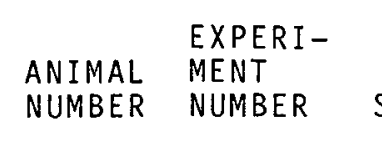

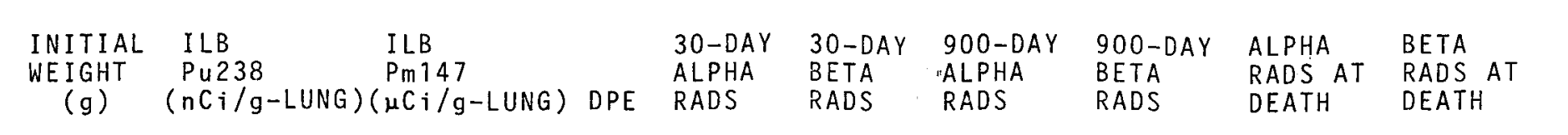

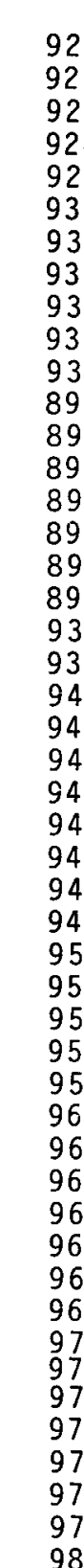

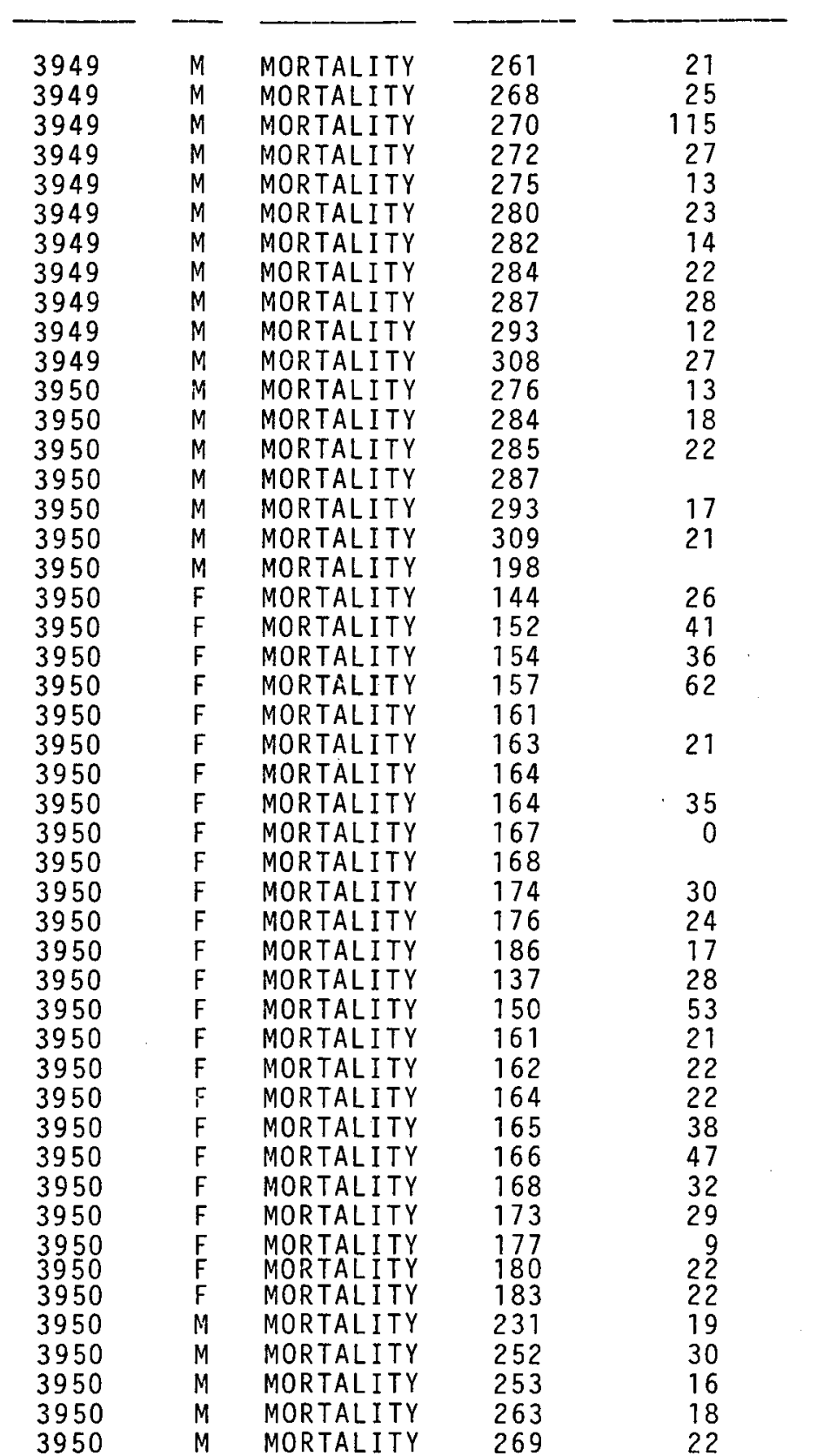

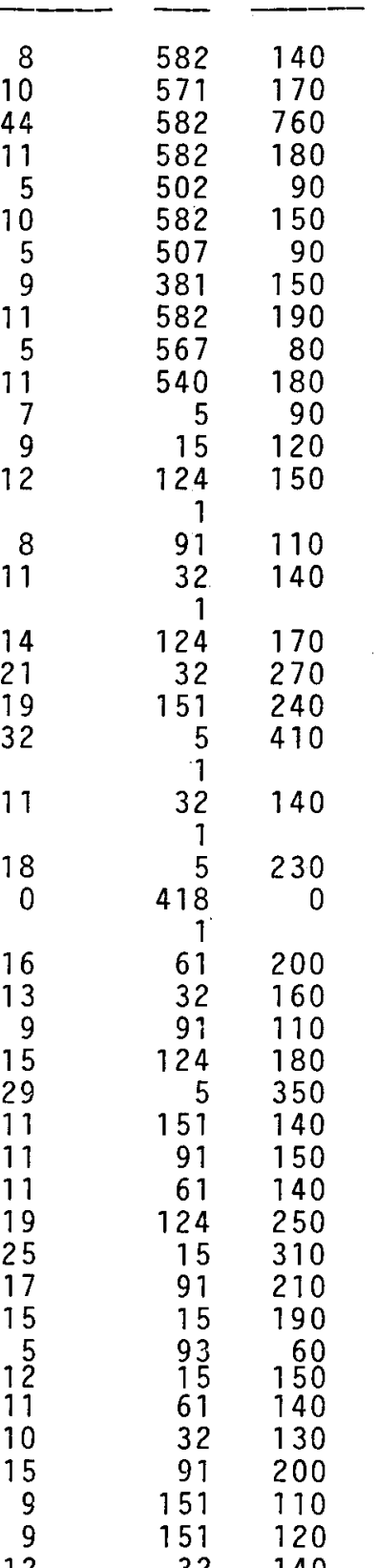

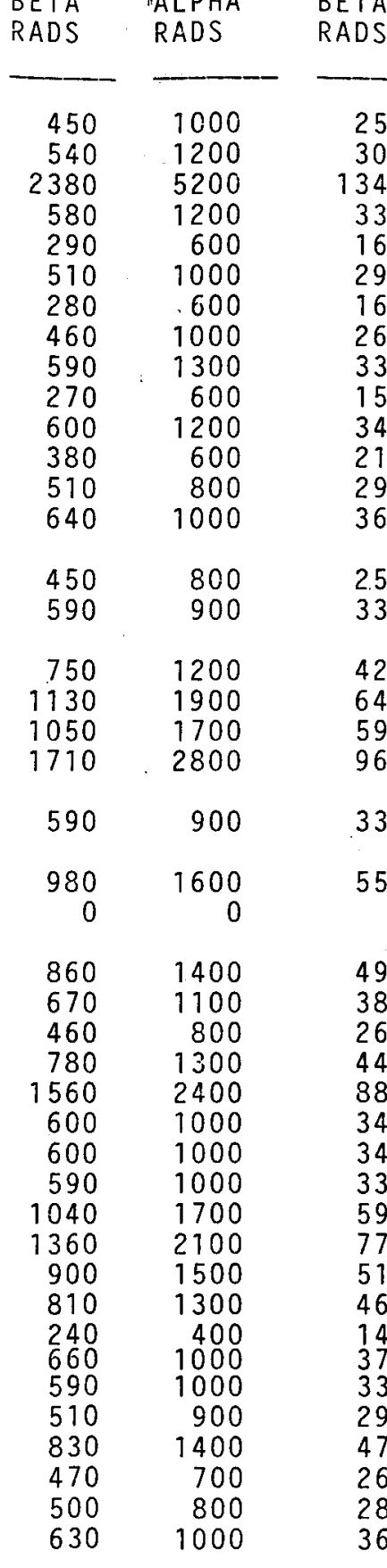

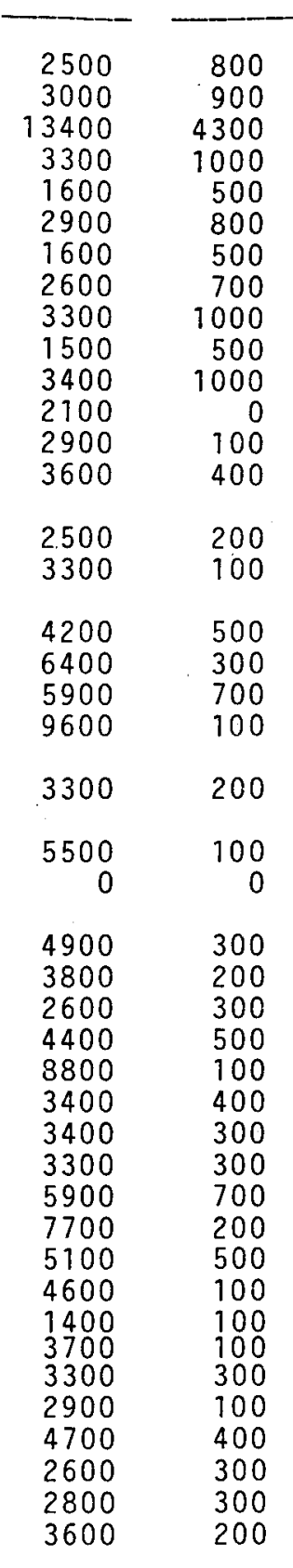
MODE OF DEATH

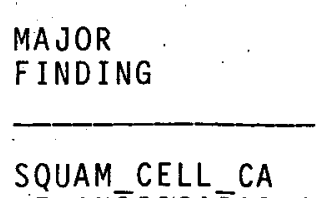
OtHER FindiNGS AT DEATH

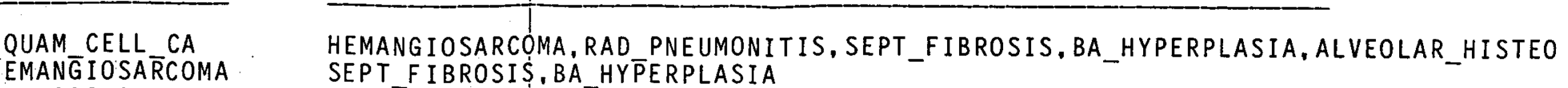

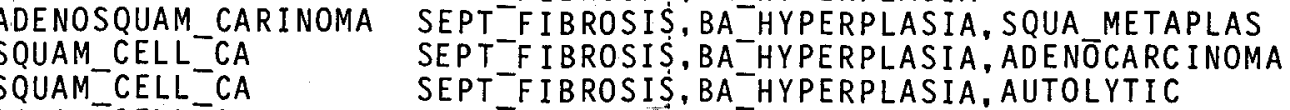

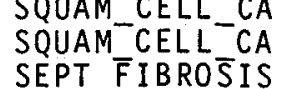

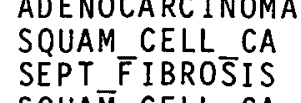

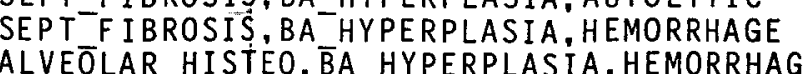

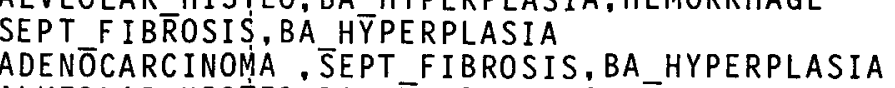

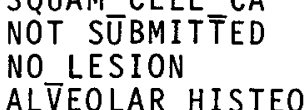
ALVELAR TISTEO, BA HYPERPLASIA

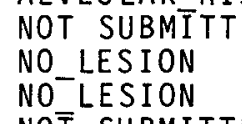

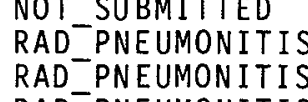
RAD PNEUMONITS
NOT SOBMTTED
NOT SUBMITTED
ALVEOLAR HISTEO
NOT SUBMTTED
NOT SUBMITTED
COTSTIED
CONGESTION
NOT SUBMITI
ATE
ALVELAR HISTEO
ALVEOLAR HISTEO
ALVELAR-HISTEO
NOT SUBMT TTED
ALEOLAR HISTEO
ALEOLA HITSEO
ALVEOLAR
NOSSTEO
NO LESTOM. AUTOLYIC
NOT̄ SUBMTTTEO
NO LESIOMTTE
NOT SUBMTT

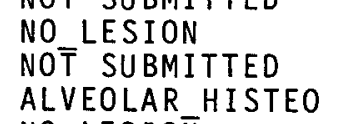
AUTOLYTIC
ALVEOLAR HISTO
NO LES ION
NO-LESION 
OTHER FINDINGS AT DEATH 


\begin{tabular}{|c|c|c|c|c|c|c|c|c|c|c|c|c|}
\hline $\begin{array}{l}\text { ANIMAL } \\
\text { HUMBER }\end{array}$ & $\begin{array}{l}\text { EXPERI- } \\
\text { MENT } \\
\text { NUMBER }\end{array}$ & SEX & $\begin{array}{l}\text { 110:THS } \\
\text { AFTER } \\
\text { EXPOSURE }\end{array}$ & $\begin{array}{c}I L B \\
P u-238 \\
(n C i / g-L U N G) \\
\end{array}$ & $\begin{array}{c}I L B \\
P m-147 \\
(\mu C i / q-L U N G)\end{array}$ & $\begin{array}{l}\text { ALPHA } \\
\text { RADS } \\
\end{array}$ & $\begin{array}{l}\text { BETA } \\
\text { RADS } \\
\end{array}$ & $\begin{array}{l}\text { VITAL } \\
\text { CAPAC. } \\
\text { (mI) }\end{array}$ & $\begin{array}{l}\text { CO DIF- } \\
\text { FUSING } \\
\text { CAPAC. } \\
(\mathrm{ml} / \mathrm{min} / \\
\mathrm{mm} \mathrm{Hg}) \\
\end{array}$ & $\begin{array}{l}\text { DEFUSIAD } \\
\text { CAPACITY } \\
\text { PERKG } \\
\text { BODY WT } \\
\end{array}$ & $\begin{array}{l}\text { OUAJISTATIC } \\
\text { COHPLIANCE } \\
\left(\mathrm{MI} / \mathrm{CM}-\mathrm{H}_{2} \text { O) }\right.\end{array}$ & $\begin{array}{l}\text { SLOPE } \\
\text { PHASE } \\
3 \\
\end{array}$ \\
\hline 101 & 3941 & $\mathrm{~F}$ & 18 & 0 & 0 & 0 & 0 & 10.8 & 0.19 & 0.27 & 0.81 & 0.60 \\
\hline 103 & 3941 & $\mathrm{~F}$ & 18 & 0 & 0 & 0 & 0 & 10.6 & 0.19 & 0.30 & 0.79 & 0.42 \\
\hline 105 & 3941 & $\mathrm{~F}$ & 18 & 0 & 0 & 0 & 0 & 11.7 & 0.22 & 0.87 & 0.92 & 0.69 \\
\hline 107 & 3941 & $\mathrm{~F}$ & 13 & 0 & 0 & 0 & 0 & 12.0 & 0.23 & 0.90 & 0.93 & 0.35 \\
\hline 109 & 3941 & F & 18 & 0 & 0 & 0 & 0 & 11.4 & 0.23 & 0.81 & 0.86 & 0.68 \\
\hline 111 & 3941 & $F$ & $1 \hat{\varepsilon}$ & 0 & 0 & 0 & 0 & 9.6 & 0.16 & 0.70 & 0.73 & 0.51 \\
\hline 113 & 3941 & $\mathrm{~F}$ & 18 & 0 & 0 & 0 & 0 & 11.2 & 0.22 & 0.92 & 0.85 & 0.47 \\
\hline 115 & 3941 & $\mathrm{~F}$ & 18 & 0 & 0 & 0 & 0 & 11.9 & 0.23 & 0.75 & 0.89 & 0.49 \\
\hline $117^{\circ}$ & 3941 & $\mathrm{~F}$ & 18 & 0 & 0 & 0 & 0 & 12.5 & 0.22 & 0.67 & 1.00 & 0.52 \\
\hline 118 & 3941 & $\mathrm{~F}$ & 18 & 0 & 0 & 0 & 0 & 13.7 & 0.25 & 0.79 & 1.10 & 0.27 \\
\hline 119 & 3941 & i.1. & 18 & 0 & 0 & 0 & 0 & 14.3 & 0.25 & 0.77 & 1.03 & 0.48 \\
\hline 121 & 3941 & 4 & 18 & 0 & 0 & 0 & 0 & 14.8 & 0.31 & 0.84 & 1.06 & 0.51 \\
\hline 123 & $394 ?$ & M & 18 & 0 & 0 & 0 & 0 & 17.1 & 0.35 & 0.79 & 1.30 & 0.48 \\
\hline 126 & 3941 & $M$ & 18 & 0 & 0 & 0 & 0 & 16.9 & 0.33 & 0.55 & 1.22 & 0.44 \\
\hline 127 & 3941 & $M$ & 18 & 0 & 0 & 0 & 0 & 16.1 & 0.30 & 3.74 & i. 21 & 0.45 \\
\hline 129 & 3941 & $M$ & 18 & 0 & 0 & 0 & 0 & 17.1 & 0.38 & 0.06 & 1.29 & 0.38 \\
\hline 131 & 3941 & $M$ & 18 & 0 & 0 & 0 & 0 & 16.4 & 0.27 & 0.65 & 1.27 & 0.28 \\
\hline 133 & 3941 & M & 18 & & & 0 & 0 & 15.6 & 0.18 & 0.44 & 1.17 & 0.40 \\
\hline 135 & 3941 & M & 18 & 0 & 0 & 0 & 0 & 16.5 & 0.35 & 0.74 & 1.26 & 0.42 \\
\hline 136 & 3941 & $M$ & 18 & 0 & 0 & 0 & 0 & 15.1 & 0.36 & 0.74 & 1.13 & 0.56 \\
\hline 201 & 3942 & F & 18 & 115 & 0 & 4300 & 0 & 4.9 & 0.06 & 0.27 & 0.28 & 9.01 \\
\hline 203 & 3942 & F & 18 & 141 & 0 & 5200 & 0 & 4.9 & 0.04 & 0.23 & 0.30 & 8.66 \\
\hline 205 & 3942 & F & 18 & 139 & 0 & 5200 & 0 & 5.2 & 0.06 & 0.24 & 0.32 & 7.65 \\
\hline 209 & 3942 & $\mathrm{~F}$ & 18 & 114 & 0 & 4200 & 0 & 4.6 & 0.05 & 0.27 & 0.27 & 8.82 \\
\hline 213 & 3942 & $\mathrm{~F}$ & 18 & 115 & 0 & 4300 & 0 & 6.5 & 0.08 & 0.34 & 0.46 & 3.20 \\
\hline 230 & 3942 & $M$ & 18 & 77 & 0 & 2900 & 0 & 11.1 & 0.19 & 0.48 & 0.84 & 0.86 \\
\hline 301 & 3943 & $\mathrm{~F}$ & 18 & 25 & 0 & 930 & 0 & 9.2 & 0.14 & 0.65 & 0.67 & 0.78 \\
\hline 302 & 3943 & $\mathrm{~F}$ & 18 & 34 & 0 & 1300 & 0 & 9.9 & 0.17 & 0.67 & 0.69 & 0.58 \\
\hline 303 & 3943 & $\mathrm{~F}$ & 18 & 19 & 0 & 700 & 0 & 10.6 & 0.19 & 0.73 & 0.80 & 0.77 \\
\hline 304 & 3943 & $F$ & 18 & 39 & 0 & 1500 & 0 & 7.2 & 0.12 & 0.48 & 0.50 & 1.37 \\
\hline 305 & 3943 & $F$ & 18 & 26 & 0 & 960 & 0 & 9.8 & 0.17 & 0.69 & 0.75 & 0.57 \\
\hline 307 & 3943 & $F$ & 18 & 30 & 0 & 1100 & 0 & 10.0 & 0.18 & 0.69 & 0.74 & 0.47 \\
\hline 309 & 3943 & $F$ & $1 \varepsilon$ & 22 & 0 & 820 & 0 & 10.7 & 0.18 & 0.70 & 0.81 & 0.48 \\
\hline 312 & 3943 & $\mathrm{~F}$ & 18 & 24 & 0 & 890 & 0 & 10.5 & 0.15 & 0.50 & 0.77 & 0.45 \\
\hline 313 & 3943 & $\mathrm{~F}$ & 18 & 22 & 0 & 820 & 0 & 11.1 & 0.21 & 0.85 & 0.34 & 0.73 \\
\hline 314 & 3943 & $\mathrm{~F}$ & 18 & 18 & 0 & 670 & 0 & 11.1 & 0.22 & 0.33 & 0.85 & 0.39 \\
\hline 319 & 3943 & in & 18 & 27 & 0 & 1000 & 0 & 9.1 & 0.15 & 0.48 & 0.72 & 0.77 \\
\hline 320 & 3943 & $M$ & $1 \varepsilon$ & 30 & 0 & 1100 & 0 & 15.0 & 0.31 & 0.83 & 1.13 & 0.46 \\
\hline 327 & 3943 & 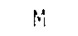 & 18 & 34 & 0 & 1300 & 0 & 12.2 & 0.26 & 0.72 & 0.84 & 0.64 \\
\hline 325 & 3943 & $M$ & is & 18 & 0 & 670 & 0 & 11.8 & 0.23 & 0.62 & 0.95 & 0.30 \\
\hline 328 & 3943 & $M$ & $1 \varepsilon$ & 20 & 0 & 740 & 0 & 13.8 & 0.27 & 0.61 & 1.08 & 0.50 \\
\hline 330 & 3943 & $M$ & 18 & 21 & 0 & 780 & 0 & 14.4 & 0.35 & 0.87 & 1.10 & 0.54 \\
\hline 331 & 3943 & lit & 18 & 26 & 0 & 960 & 0 & 15.7 & 0.27 & $0.6 ?$ & 3.24 & 0.36 \\
\hline 332 & 3943 & ii & 18 & 19 & 0 & 700 & 0 & 11.9 & 0.21 & 0.53 & 0.84 & 0.72 \\
\hline 333 & 3943 & M & 18 & 20 & 0 & 740 & 0 & 15.6 & 0.30 & 0.68 & 1.19 & 0.48 \\
\hline 407 & 3944 & $F$ & 18 & 0 & 59 & 0 & 11000 & 7.2 & 0.1 & 0.47 & 0.46 & 2.22 \\
\hline 408 & 3944 & F & 18 & 0 & 56 & 0 & 11000 & 7.6 & 0.14 & 0.56 & 0.49 & 0.82 \\
\hline 410 & 3944 & F & 18 & 0 & 35 & 0 & 6600 & 5.1 & 0.10 & 0.39 & 0.37 & 8.22 \\
\hline 416 & 3944 & f & 18 & 0 & 53 & 0 & 9900 & 8.5 & 0.15 & 0.53 & 0.59 & 1.04 \\
\hline 418 & 3944 & $F$ & 18 & 0 & 30 & 0 & 7100 & 10.0 & 0.18 & 0.69 & 0.78 & \\
\hline 419 & 3944 & $\because i$ & 18 & 0 & 67 & 0 & 13000 & 12.2 & 0.26 & 0.67 & 0.83 & 0.72 \\
\hline 422 & 3944 & $\because i$ & 13 & 0 & 64 & 0 & 12000 & 8.0 & 0.15 & 0.42 & 0.54 & 9.66 \\
\hline 429 & 3944 & in & 18 & 0 & 49 & 0 & 9200 & 15.4 & 0.27 & 0.61 & 1.17 & 0.36 \\
\hline 430 & 3944 & 11 & 18 & 0 & 28 & 0 & 5200 & 12.7 & 0.23 & 0.58 & 0.97 & 0.69 \\
\hline 431 & 3944 & i. & 18 & 0 & 27 & 0 & 5100 & 13.0 & 0.31 & 0.74 & 0.94 & 0.70 \\
\hline
\end{tabular}


2B. PULMONARY FUNCTION MEASUREMENTS FOR RATS EXPOSED VIA INHALATION TO $238 \mathrm{Pu}, 147 \mathrm{Pm}$ OR BOTH IN FAP

\begin{tabular}{l} 
EXPERI- \\
MENT \\
NUMBER \\
\hline 3944 \\
3944 \\
3944 \\
3945 \\
3945 \\
3945 \\
3945 \\
3945 \\
3945 \\
3945 \\
3945 \\
3945 \\
3945 \\
3945 \\
3945 \\
3945 \\
3945 \\
3945 \\
3945 \\
3947 \\
3947 \\
3947 \\
3947 \\
3947 \\
3947 \\
3947 \\
3947 \\
3947 \\
3947 \\
3947 \\
3947 \\
3947 \\
3947 \\
3947 \\
3947 \\
3947 \\
3947 \\
3947 \\
3949 \\
3949 \\
3949 \\
3949 \\
3949 \\
\end{tabular}

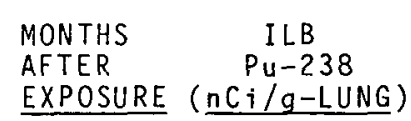

NUMBER

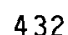

432
433
436

436
501

501
502

504
507

508

509

510

511
513

514

519

521
522

523

524

525
702

702
704

705
706

706
707

708

711
712

713

715

716
717

717
718

719
725

725
726

726

731

732

909
920

922
928

930
( $\mathrm{C}$ i/g-LUNG) ALPHA

$\begin{array}{llrl}18 & 0 & 38 & 0 \\ 18 & 0 & 52 & 0 \\ 18 & 0 & 39 & 0 \\ 18 & 0 & 22 & 0 \\ 18 & 0 & 20 & 0 \\ 18 & 0 & 19 & 0 \\ 18 & 0 & 6 & 0 \\ 18 & 0 & 7 & 0 \\ 18 & 0 & 9 & 0 \\ 18 & 0 & 7 & 0 \\ 18 & 0 & 12 & 0 \\ 18 & 0 & 31 & 0 \\ 18 & 0 & 29 & 0 \\ 18 & 0 & 10 & 0 \\ 18 & 0 & 6 & 0 \\ 18 & 0 & 9 & 0 \\ 18 & 0 & 14 & 0 \\ 18 & 0 & 13 & 0 \\ 18 & 0 & 35 & 0 \\ 18 & 34 & 53 & 1200\end{array}$

0
1200
650

650
540
900

540
900
760

760
830

1200

720

680
1000
680
760

680
760
720

720
1200
900
1000

650

680

970

970
760
680

680

970

830

CO DIF-

FUSING DIFFUSING

VITAL CA]AC. CAPACITY QUASISTATIC SLOPE

CAPAC. $(\mathrm{m} 7 / \mathrm{min} / \mathrm{PER} \mathrm{Kg}$ COMPLIANCE PHASE

(ml) $\mathrm{mm} \mathrm{Hg})$ BOOY WT $\left(\mathrm{ml} / \mathrm{cm}-\mathrm{H}_{2} \mathrm{O}\right)$

7100

12.3

0.21

0.53

0.93

$\frac{3}{0.59}$

9700

4100

4100
3700

3600

1100

1300

1700
1300

2200

5800

5400

1900

1100

2600

2400

6600

15000
8300

6600

11000

9400

15000

9100

8500

13000

8500

8800

8800
14000

11000

13000

7700

8300

12000

3000
2200

2200
2200

3000

2800

0.22

0.57

0.93

0.59
0.75

8.6

0.14

0.63

1.08

0.75

11.5

0.19

0.85
0.71

0.67
0.87

0.87

0.68

11.2

0.20

0.76

0.80

0.76

0.19

12.6

0.23

0.77

0.75

0.63

12.7

0.21

0.85
0.77

0.77

0.39
0.71

0.94

0.88

11.8
12.3

0.10

0.31

0.86

0.99

0.88

0.87

0.45

0.74

0.77

0.75

0.77

0.24

0.68

0.60
0.48

0.48
0.29

0.29

0.31

0.59

0.52

0.33

0.49

0.54
0.40

0.40
0.32

0.32
0.55

0.38

0.38
0.55

0.56

0.33

0.48

0.68

0.38

0.50
0.38

1.03

1.28

1.17

1.09

1.10

0.28

0.67
0.65

0.69

0.33

0.38

0.41

0.55

0.57

0.43

0.57
0.66

0.49

0.60

0.67

0.52

1.03

0.78

0.53

1.14
0.88

0.78
0.76

0.76
0.70

0.65

0.74

0.52

0.51
0.42

0.50

0.52

0.32

0.47

0.34

12.06

12.06

0.73

0.58

5.62

2. 47

5.09

1.13

1.35

3.49

0.68

0.80

1. 24

1.55
1.39

1.92

0.52

0.78

1.51

$9.5 \quad 0.14$

0.38

0.39
0.67

0.86

0.86
1.26 